\title{
Traducción
}

\section{Soberanía alimentaria desde el territorio: aprovisionamiento, prácticas cotidianas y el papel de las mujeres afrocolombianas en el mantenimiento de sistemas alimentarios ${ }^{1}$}

\author{
Translation
}

\section{Food sovereignty, gender and everyday practice: the role of Afro-Colombian women in sustaining localised food systems}

\author{
Katherine L. Turner ${ }^{2}$ \\ Universidad de Victoria, Canadá \\ (i) https://orcid.org/0000-0001-8727-5506 \\ C. Julián Idrobo ${ }^{3}$ \\ Universidad de British Columbia, \\ Canadá \\ (D) https://orcid.org/0000-0003-1971-1462
}

\author{
Annette Aurélie Desmarais ${ }^{4}$ \\ Universidad de Manitoba, Canadá \\ (iD) https://orcid.org/0000-0002-9274-8838
}

\author{
Ana María Peredo 5 \\ Universidad de Ottawa y Universidad de \\ Victoria, Canadá \\ (iD) https://orcid.org/0000-0002-5534-4834
}

\begin{abstract}
Resumen: Si bien los movimientos sociales y políticos son generalmente el ámbito de las luchas por la soberanía alimentaria, las prácticas cotidianas de aprovisionamiento son fundamentales para la persistencia de sistemas alimentarios locales y relativamente autónomos. En esta investigación examinamos el aprovisionamiento desde una perspectiva de género en una comunidad colombiana afrodescendiente como un caso de estudio de "soberanía alimentaria desde el territorio". Encontramos que las prácticas cotidianas de aprovisionamiento de las mujeres sostienen los hogares, mantienen las relaciones socioculturales y ecológicas y permiten una mayor autosuficiencia en el contexto de procesos de integración económica al mercado. Aproximarse al aprovisionamiento desde una perspectiva de género deja entrever las complejidades, relaciones de poder y
\end{abstract}

Recibido: 24/11/2020 | Disponible en línea: 19/03/2021

Cómo citar este artículo: Turner, K.L., Idrobo, C.J., Desmarais, A.A., y Peredo, A.M. (2020). Soberanía alimentaria desde el territorio: aprovisionamiento, prácticas cotidianas y el papel de las mujeres afrocolombianas en el mantenimiento de sistemas alimentarios. Jangwa Pana, 20(1), 158-185. doi: https://doi.org/10.21676/16574923.3996

\footnotetext{
${ }^{1}$ Los autores de este manuscrito manifestamos que no tenemos conflicto de intereses. Somos independientes respecto a las instituciones financiadoras y de apoyo. La planeación, diseño, trabajo de campo y redacción de ese documento se realizó sólo con interés concernientes al ejercicio investigativo. Esta investigación fue financiada por el programa de Cátedra de Investigación Canadiense en Derechos Humanos, Justicia Social y Soberanía Alimentaria (Canada Research Chair in Human Rights, Social Justice and Food Sovereignty), la beca postdoctoral del Consejo de Investigación de Ciencias Sociales y Humanidades de Canadá (Social Sciences and Humanities Research Council of Canada Postdoctoral Fellowships; Turner: \# 756-2017-03) y el Fondo de Apoyo a Profesores Asistentes (FAPA) de la Universidad de los Andes (Idrobo: \# P16.P16.303622.005/01). Una versión de este manuscrito ("Food sovereignty, gender and everyday practice: The role of Afro-Colombian women in sustaining localised food systems") se publicó en The Journal of Peasant Studies por Taylor \& Francis en agosto de 2020: https://doi.org/10.1080/03066150.2020.1786812 - Licencia Attribution 4.0 International (CC BY 4.0). Este manuscrito fue traducido del inglés al castellano por Diana Carolina Castaño-Alzate.

${ }^{2}$ Correo electrónico: katelturner@gmail.com

${ }^{3}$ Correo electrónico: cjidrobo@gmail.com

${ }^{4}$ Correo electrónico: Annette.Desmarais@umanitoba.ca

${ }^{5}$ Correo electrónico: aperedo@uvic.ca
}

Turner, K.L., Idrobo, C.J., Desmarais, A.A., y Peredo, A.M. (2020). Soberanía alimentaria desde el territorio: aprovisionamiento, prácticas cotidianas y el papel de las mujeres afrocolombianas en el mantenimiento de sistemas alimentarios. Jangwa Pana, 20(1), 158-185. doi: https://doi.org/10.21676/16574923.3996 
desafíos que subyacen a estos sistemas alimentarios locales. Indagar sobre esta dimensión frecuentemente ignorada puede contribuir a identificar y comprender mejor el aporte de las mujeres a la construcción cotidiana de la soberanía alimentaria.

Palabras clave: soberanía alimentaria; soberanía alimentaria desde el territorio; aprovisionamiento; género; prácticas cotidianas; Bajo Baudó; Pacífico Colombiano.

\begin{abstract}
While social and political movements are the scale of action most often identified with food sovereignty-related struggles, everyday provisioning practices are critical for sustaining the distinctiveness and relative autonomy of localised food systems. We examine gendered provisioning in a Colombian, Afrodescendent community as a case study of how food sovereignty is enacted in daily life. Women's everyday food provisioning practices nourish households, sustain socio-cultural and ecological relationships, and maintain greater self-sufficiency within market economy integration processes. Deeper analysis of gendered provisioning highlights complexities, power relationships and challenges within localised food systems and contributes to greater understanding of the gender dimensions of food sovereignty.
\end{abstract}

Keywords: food sovereignty; provisioning; gender; everyday practice; local food systems; Colombia; Chocó.

\title{
Introducción
}

Los movimientos sociales son el accionar social y político generalmente relacionado con las luchas por la soberanía alimentaria. Sin embargo, las prácticas cotidianas de aprovisionamiento de alimentos son fundamentales para mantener sistemas alimentarios locales y para ejercer cierto grado de autonomía del sistema alimentario global. Generalmente, dentro del ámbito del aprovisionamiento, las mujeres desempeñan labores puntuales pero significativas que son invisibilizadas dentro de los hogares y subestimadas por parte de las autoridades, catalogándolas como actividades secundarias o menos importantes con respecto a aquellas orientadas al mercado (Lemke y Delormier, 2017). Reconocer las contribuciones de las prácticas cotidianas de aprovisionamiento de alimentos llevadas a cabo por mujeres reivindica una dimensión de las luchas por la soberanía alimentaria que no ha recibido la suficiente atención. Proponemos el término "soberanía alimentaria desde el territorio" con el fin de resaltar esta dimensión de la soberanía alimentaria.

El estudio de las prácticas de aprovisionamiento desde una perspectiva de género en una comunidad afrodescendiente del Pacífico colombiano nos permite afirmar que prestar mayor atención a las prácticas cotidianas de las mujeres brinda información valiosa sobre cómo se mantienen y reproducen los sistemas alimentarios locales. Estas prácticas representan en sí mismas una forma de resistencia frente a fuerzas que favorecen la globalización de la producción y consumo de alimentos (IPBES-Food, 2016). En este orden de ideas, en nuestro análisis del aprovisionamiento en un sistema alimentario local identificamos varias actividades en las que las mujeres son las actoras principales. Estas actividades no sólo proporcionan el sustento de sus familias, sino que también permiten el acceso a alimentos de importancia cultural, mantienen relaciones socio-culturales, tradiciones y conocimientos ecológicos asociados al aprovisionamiento de alimentos. Las prácticas cotidianas de aprovisionamiento de las mujeres son una expresión única y poderosa de trabajo por la soberanía alimentaria, el cual es vital para la capacidad funcional de los sistemas alimentarios locales. Un reconocimiento más profundo y un compromiso con la soberanía alimentaria desde el territorio representada en las prácticas de aprovisionamiento desde una dimensión de género deja entrever las complejidades, relaciones de poder y desafíos que subyacen a 
estos sistemas alimentarios. Indagar sobre estos componentes, a menudo subvalorados, puede ayudarnos a identificar y comprender mejor la relevancia de los aportes de las mujeres a la soberanía alimentaria.

\section{Una perspectiva de la soberanía alimentaria desde el territorio: vida cotidiana, aprovisionamiento de alimentos y resistencia}

La soberanía alimentaria se define en términos generales como "el derecho de las naciones y de los pueblos a controlar sus sistemas alimentarios propios, incluyendo sus propios mercados, modos de producción, culturas alimentarias y ambientes..." (Wittman et al., 2010, p. 2), y se orienta explícitamente a la transformación del sistema alimentario global, neoliberal e industrial basado en el capitalismo. Es un marco político radical enfocado en la re-incorporación de los sistemas alimentarios con el fin de que las comunidades locales tengan más control y poder de decisión sobre las formas y medios de producción, distribución y consumo de alimentos. La soberanía alimentaria hace énfasis en una completa realización del derecho a unos medios de vida de campesinos, trabajadores agrícolas, pequeños agricultores y otros habitantes del campo, a la vez que prioriza la gestión ambiental. En este contexto, a mediados de los noventa, el movimiento agrario transnacional La Vía Campesina articuló por primera vez el concepto campesino de soberanía alimentaria a partir del cual ha trabajado con el fin de consolidar un movimiento social global de resistencia para la construcción de alternativas al régimen alimentario neoliberal (Desmarais, 2007). En esta escala de acción -a menudo relacionada con los movimientos sociales globales, regionales, nacionales y/o subnacionales, cumbres internacionales, campañas nacionales, protestas y leyes- se enfocan cada vez más un número mayor de académicos y es en torno a la cual se articula el discurso y el concepto de soberanía alimentaria. ${ }^{6}$

\section{Soberanía alimentaria en la práctica cotidiana}

La resistencia de La Vía Campesina ha ampliado la comprensión de los impactos socioculturales, ecológicos y económicos de la globalización neoliberal, y ha promovido una mayor conciencia sobre las luchas campesinas y de pequeños productores de alimentos que buscan la justicia social y ambiental. Sin embargo, se ha prestado menos atención a las realidades, en ocasiones problemáticas, sobre cómo se materializan las luchas por la soberanía alimentaria en la práctica cotidiana de personas cuyo trabajo sostiene el funcionamiento de sistemas alimentarios locales particulares. En su reflexión sobre la importancia de esta dimensión local de la soberanía alimentaria, Robbins $(2015$, p. 452) señala que:

La soberanía alimentaria es un discurso político, una propuesta y, en cierto modo, una descripción abstracta de un sistema deseado de producción, distribución y consumo agrícola, y de relaciones sociales. En otras palabras, la soberanía alimentaria es una práctica desde el territorio constituida por una serie de pasos políticos, económicos y

\footnotetext{
${ }^{6}$ Debido a limitaciones de espacio, no podemos mostrar ampliamente toda esta literatura tan rica y extensa. En lugar de esto, animamos a los lectores a buscar las siguientes revistas en las cuales se han publicado numerosos artículos sobre soberanía alimentaria: The Journal of Peasant Studies, Globalizations, Agriculture and Human Values, Third World Quarterly y Canadian Journal of Development Studies, entre otras.
}

Turner, K.L., Idrobo, C.J., Desmarais, A.A., y Peredo, A.M. (2020). Soberanía alimentaria desde el territorio: aprovisionamiento, prácticas cotidianas y el papel de las mujeres afrocolombianas en el mantenimiento de sistemas alimentarios. Jangwa Pana, 20(1), 158-185. doi: https://doi.org/10.21676/16574923.3996 
sociales concretos en pro de una visión particular del sistema alimentario y de los actores involucrados. (Énfasis añadido)

Investigaciones recientes interesadas en esta dimensión de la soberanía alimentaria abarcan lo que se considera empírica y teóricamente como parte del movimiento por la soberanía alimentaria. Estos estudios se han referido a una "soberanía alimentaria silenciosa" (Visser, et al., 2015), "soberanía alimentaria local" (Ayres y Bosia, 2011), "soberanía alimentaria cotidiana" o soberanía alimentaria "centrada en las personas" (Figueroa, 2015), y a una "experiencia vivida de soberanía alimentaria" (Ngcoya y Kumarakulasingam, 2017). Estas aproximaciones, aunque distintas, confluyen en un énfasis en la práctica a escala micro y local, la experiencia vivida y la construcción de significado local y situado dentro de los procesos y estructuras regionales, nacionales y globales más amplias. En este trabajo, nosotros proponemos una "soberanía alimentaria desde el territorio" como una forma de reconocer las luchas de familias y comunidades por la alimentación arraigadas en las prácticas y actividades cotidianas que mantienen el control sobre los sistemas alimentarios locales.

El uso del término soberanía alimentaria desde el territorio hace énfasis en: (1) el lugar y contexto específico de las expresiones de soberanía alimentaria que reflejan ecologías, culturas e historias locales, y (2) la noción de estar arraigado en la vida y práctica cotidiana ${ }^{7}$. Así, la soberanía alimentaria desde el territorio reconoce la historicidad de los sistemas alimentarios (McMichael, 2009) y la importancia de la experiencia vivida en el entendimiento de cómo el capitalismo y el régimen alimentario neoliberal se han asimilado, negociado y resistido (Figueroa, 2015). La soberanía alimentaria desde el territorio no debe interpretarse erróneamente como un proceso que carece de los fundamentos políticos de la soberanía alimentaria. Más allá de esto, y basándonos en las ideas de Scott (1985), Fanon (2008) y otros (Gibson-Graham, 2008; Ong, 2010), las heurísticas de la vida cotidiana son las que dirigen la atención a la construcción de significado en torno a las prácticas de aprovisionamiento de alimentos y sobre cómo los cambios sociales y ambientales, producidos por procesos históricos de colonización, marginación y explotación, recientemente bajo la expansión del capitalismo y de políticas neoliberales, son experimentados, reproducidos, negociados, asimilados y resistidos a través de lo que puede considerarse como "actos banales de subsistencia diaria" (Figueroa, 2015, p. 502).

Los sistemas alimentarios deben examinarse ante todo en términos de su vida social, de ahí que "la comida [sea] una forma en [la] que el capitalismo se vive y se hace tangible en la experiencia cotidiana" (Figueroa, 2015, p. 503). Así, la expansión del capitalismo se ve reflejada en los sistemas alimentarios a través de la demanda creciente de efectivo, competencia entre pequeños productores de alimentos en el mercado, migración ruralurbana, privatización de la tierra y los recursos, flujos de remesas, entre otros procesos (Akram-Lodhi y Kay, 2009; Figueroa, 2015; Magdoff, et al., 2000). Por esto, entender cómo los pequeños productores de alimentos negocian su autonomía en el marco del modo de

\footnotetext{
${ }^{7}$ Tomar la experiencia vivida y las perspectivas locales como punto de entrada para analizar y comprender procesos más grandes que hacen eco del enfoque filosófico articulado con la teoría anclada (Creswell, 2014).

Turner, K.L., Idrobo, C.J., Desmarais, A.A., y Peredo, A.M. (2020). Soberanía alimentaria desde el territorio: aprovisionamiento, prácticas cotidianas y el papel de las mujeres afrocolombianas en el mantenimiento de sistemas alimentarios. Jangwa Pana, 20(1), 158-185. doi: https://doi.org/10.21676/16574923.3996
} 
producción capitalista se reconoce como un proceso vital de resistencia dentro de la literatura de nuevos campesinados (van der Ploeg, 2018).

Teniendo en cuenta la creatividad cotidiana, las acciones y tácticas que las personas emplean para asegurar su supervivencia y analizando cómo ellas construyen sistemas alimentarios resilientes y vidas deseables, también se pueden identificar estrategias que escapan a la arquitectura de control del régimen alimentario neoliberal (Davidson-Hunt, et al. 2017; Figueroa, 2015; Lewis, 2016; Robbins, 2015; van der Ploeg, 2018). Por ejemplo, el trabajo de Lewis (2016) sobre la cocina doméstica de las mujeres en Sudáfrica demuestra que, si bien estas responsabilidades son generalmente parte de los roles sociales prescritos para las mujeres, los cuales subordinan su labor reproductiva dentro de estructuras capitalistas y patriarcales, algunas mujeres encuentran que estas prácticas cotidianas pueden proporcionar espacios de agencia creativa, satisfacción, autoridad e influencia dentro del hogar, así como dentro de esferas sociales más amplias determinando deseos, emociones y relaciones. Para ampliar este panorama de funcionamiento del poder, no solo de arriba hacia abajo sino a través de una agencia individual y colectiva, la soberanía alimentaria puede entenderse mejor como un concepto relacional en el que "la soberanía no es un objeto que existe, es un proceso vivo" (Iles y Montenegro de Wit, 2015, p. 482) al que subyace una complejidad que opera entretejiendo relaciones en múltiples niveles. La soberanía alimentaria se debe abordar como un proceso material e histórico que refleja la relacionalidad de las historias de las personas, su lugar y posición dentro de fuerzas y estructuras de poder mucho más grandes. Grey y Patel (2015) profundizan en la consideración de los movimientos indígenas y su relación con la soberanía alimentaria. Ellos concluyen que, para los pueblos indígenas, la soberanía alimentaria es parte de una larga historia de resistencia y luchas por la descolonización con el fin de restaurar sus economías tradicionales, recuperar el control sobre recursos y tierras ancestrales, y promulgar un desafío ontológico en respuesta a la cosmovisión modernacartesiana.

\section{Aprovisionamiento, género y resistencia}

El enfoque economicista que dirige y domina la formulación de políticas nacionales e internacionales para el crecimiento de "la economía" es claramente un factor que contribuye a la marginación y a los intentos por eliminar aquellos aspectos no comerciales de economías tradicionales. Es así como el análisis económico estándar tiende a oscurecer las redes de valores sociales y culturales en las que se "incrustan" las economías, las cuales rigen las actividades de producción y los medios de distribución como parte de las estrategias de subsistencia. En este artículo usaremos el término "aprovisionamiento" que se asocia generalmente a esta forma de entender la economía (Narotzky, 2005). En este orden de ideas, las economías tradicionales articulan las dinámicas entre las actividades de producción y distribución y sus dimensiones religiosas, sociales, culturales, etc. Estas economías son expresiones centrales de identidad, comunidad, cultura y de valores que son fundamentales para las luchas de los pueblos indígenas y locales por la autodeterminación y el anticolonialismo.

Otro sesgo en el análisis del aprovisionamiento asume que las prácticas de "subsistencia" son sistemas sencillos que se asocian con la privación. Los pueblos indígenas y académicos, como Sahlins $(1972,1998)$ y otros (e.g., Knokkanen, 2011; Peredo y McLean, 2013), han 
criticado fuertemente esta noción. Sahlins, por ejemplo, sostiene que las sociedades cazadoras-recolectoras a menudo disfrutaban de su propia noción de riqueza mientras producían y distribuían materiales de importancia estética, religiosa y social. Además, las economías de subsistencia son multifacéticas e incluyen el comercio y los "mercados", aunque estos no son mercados donde los precios se establezcan por oferta y demanda. Los mercados y otros intercambios se basan en el valor de uso de lo que es intercambiado. La lógica detrás del intercambio no es la acumulación de capital, sino la satisfacción de las necesidades y el mantenimiento de las relaciones sociales (Sahlins, 1972). Esta idea se refleja en la definición de Kuokkanen (2011, p. 219) de economías indígenas como:

...sistemas económicos tradicionales y locales de los pueblos indígenas que incluyen una variedad de prácticas y actividades económicas a pequeña escala basadas en la tierra así como en el manejo sostenible de los recursos... En el centro de la actividad económica no está el intercambio con fines de lucro o por competencia sino el mantenimiento de los individuos, de las familias y de la comunidad.

Las economías tradicionales son un objetivo de la modernización, el colonialismo y la expansión capitalista. Así, los esfuerzos por desestabilizar, socavar y prohibir las actividades dentro de las economías tradicionales tienen una larga historia y han tomado muchas formas, como el despojo de tierras y recursos o el discurso modernista que con frecuencia denigra las prácticas de subsistencia y otras actividades tradicionales al calificarlas de ineficientes, intrascendentes o relegadas al "atraso" y la "pobreza" (Kuokkanen, 2011; Peredo y McLean, 2013). Estas presiones convergentes obstaculizan la participación en la economía de mercado de aquellos involucrados en economías tradicionales. Sin embargo, en lugar de desaparecer, muchos pueblos locales e indígenas contemporáneos que viven en áreas rurales y remotas operan dentro de economías mixtas en las que se combinan mercados capitalistas con otras prácticas de aprovisionamiento como parte de sus medios de vida (Peredo y Chrisman, 2006). Aunque esta relación e interdependencia entre sistemas económicos con frecuencia se malinterpreta, la defensa del aprovisionamiento no capitalista es un aspecto fundamental no sólo para las luchas políticas colectivas por la autodeterminación, descolonialización y el derecho a territorios tradicionales, sino también para las luchas inmediatas por la supervivencia y el bienestar de los individuos, las familias y las comunidades. Estas ideas discutidas anteriormente son importantes para examinar la soberanía alimentaria en el contexto de las comunidades afrocolombianas.

En diversos lugares, frecuentemente las mujeres desempeñan papeles particulares pero importantes para las economías de aprovisionamiento (Federici, 2014; Howard, 2003; Kuokkanen, 2011; PWESCR, 2011). Las mujeres tienden a poseer un conocimiento ecológico tradicional especializado que es diferente al de los hombres. Ellas son las encargadas de realizar distintas actividades que varían entre culturas y etapas de la vida, y a menudo tienen que ver con la labor reproductiva, el manejo del hogar, el aprovisionamiento y el procesamiento de alimentos y el compartir (Howard, 2003; Sylvester et al., 2016; Wall, et al., 2018). No obstante, las contribuciones y los conocimientos de las mujeres se reconocen muy poco, no se valoran lo suficiente y no se toman en cuenta para los análisis económicos y de política (IPES Food, 2016; PWESCR, 2011; Wall et al., 2018). Así, el entramado de estructuras patriarcales y relaciones sociales capitalistas que subestiman y hacen invisible o

Turner, K.L., Idrobo, C.J., Desmarais, A.A., y Peredo, A.M. (2020). Soberanía alimentaria desde el territorio: aprovisionamiento, prácticas cotidianas y el papel de las mujeres afrocolombianas en el mantenimiento de sistemas alimentarios. Jangwa Pana, 20(1), 158-185. doi: https://doi.org/10.21676/16574923.3996 
insignificante esta labor reproductiva con frecuencia "silencian" el trabajo y el conocimiento de las mujeres. En consecuencia, ellas son particularmente vulnerables cuando el funcionamiento de los sistemas tradicionales de aprovisionamiento se ve impactado negativamente por la globalización y otras fuerzas (Federici, 2014; Kuokkanen, 2011).

Una expresión fundamental de la soberanía alimentaria desde el territorio corresponde a la práctica y el mantenimiento de sistemas de aprovisionamiento que permanecen casi independientes de las economías de mercado. El reconocimiento del importante papel de las mujeres en la soberanía alimentaria al mantener sistemas alimentarios locales, así como los grandes desafíos a los que se enfrentan en el contexto del sistema alimentario neoliberal, resalta la importancia y el valor de analizar sus contribuciones particulares dentro de los sistemas de aprovisionamiento desde una perspectiva de género a una soberanía alimentaria desde el territorio.

La equidad de género es un elemento clave de la teoría, práctica y discurso por la soberanía alimentaria; inclusive, bajo esta aproximación "los derechos de las mujeres no son negociables" (Patel, 2012). Aunque existe un vacío de investigación considerable con respecto a las dimensiones de género de la soberanía alimentaria (Agarwal, 2014; Masson, et al., 2017), es de resaltar el surgimiento de literatura prometedora. ${ }^{8}$ En este trabajo aportamos a ello mediante un análisis del papel de las mujeres para el autoabastecimiento en el Consejo Comunitario de Sivirú (Bajo Baudó, Chocó, Colombia), evidenciando la importancia de sus contribuciones a la soberanía alimentaria.

\section{Métodos}

En este documento presentamos un estudio de caso sobre el aprovisionamiento de alimentos desde una perspectiva de género en el Consejo Comunitario de Sivirú, municipio de Bajo Baudó, departamento del Chocó, noroccidente de Colombia. Los datos fueron recolectados a partir de 22 entrevistas semiestructuradas sobre medios de vida y sistemas alimentarios locales con 24 personas (13 mujeres y 11 hombres), un grupo focal con nueve piangüeras, y observación participante en hogares y en viajes de colecta llevados a cabo a comienzos del 2018. También usamos datos de la encuesta regional de hogares $(n=316)$-un subconjunto de 33 encuestados de la comunidad de Sivirú- sobre las prácticas de subsistencia basadas en recursos naturales, la cual fue realizada por el Centro de Estudios Interdisciplinarios sobre Desarrollo de la Universidad de los Andes y la Fundación MarViva, como parte del proceso de construcción del plan de manejo del Distrito Regional de Manejo Integrado (DRMI) Encanto de los Manglares del Bajo Baudó (Figura 1). Esta encuesta incluyó clasificaciones sobre la importancia del uso de los recursos y aspectos del consumo en los hogares (MarViva, 2018). Los participantes en Sivirú fueron seleccionados para las entrevistas a través de un muestreo bola de nieve y referencias de informantes clave. El grupo focal estuvo abierto a todas las piangüeras que quisieron asistir. Los participantes han recibido pseudónimos para proteger su privacidad y anonimato. Esta investigación fue aprobada por los Comités de Ética

\footnotetext{
${ }^{8}$ Vea entre otros, Park et al. (2015), Schwendler y Thompson (2017), Conway (2018), Portman (2018), Bezner-Kerr et al. (2019).
}

Turner, K.L., Idrobo, C.J., Desmarais, A.A., y Peredo, A.M. (2020). Soberanía alimentaria desde el territorio: aprovisionamiento, prácticas cotidianas y el papel de las mujeres afrocolombianas en el mantenimiento de sistemas alimentarios. Jangwa Pana, 20(1), 158-185. doi: https://doi.org/10.21676/16574923.3996 
de la Universidad de los Andes (Bogotá, Colombia) y la Universidad de Victoria (Victoria, Canadá).

Figura 1. Mapa Distrito Regional de Manejo Integrado Encanto de los Manglares Bajo

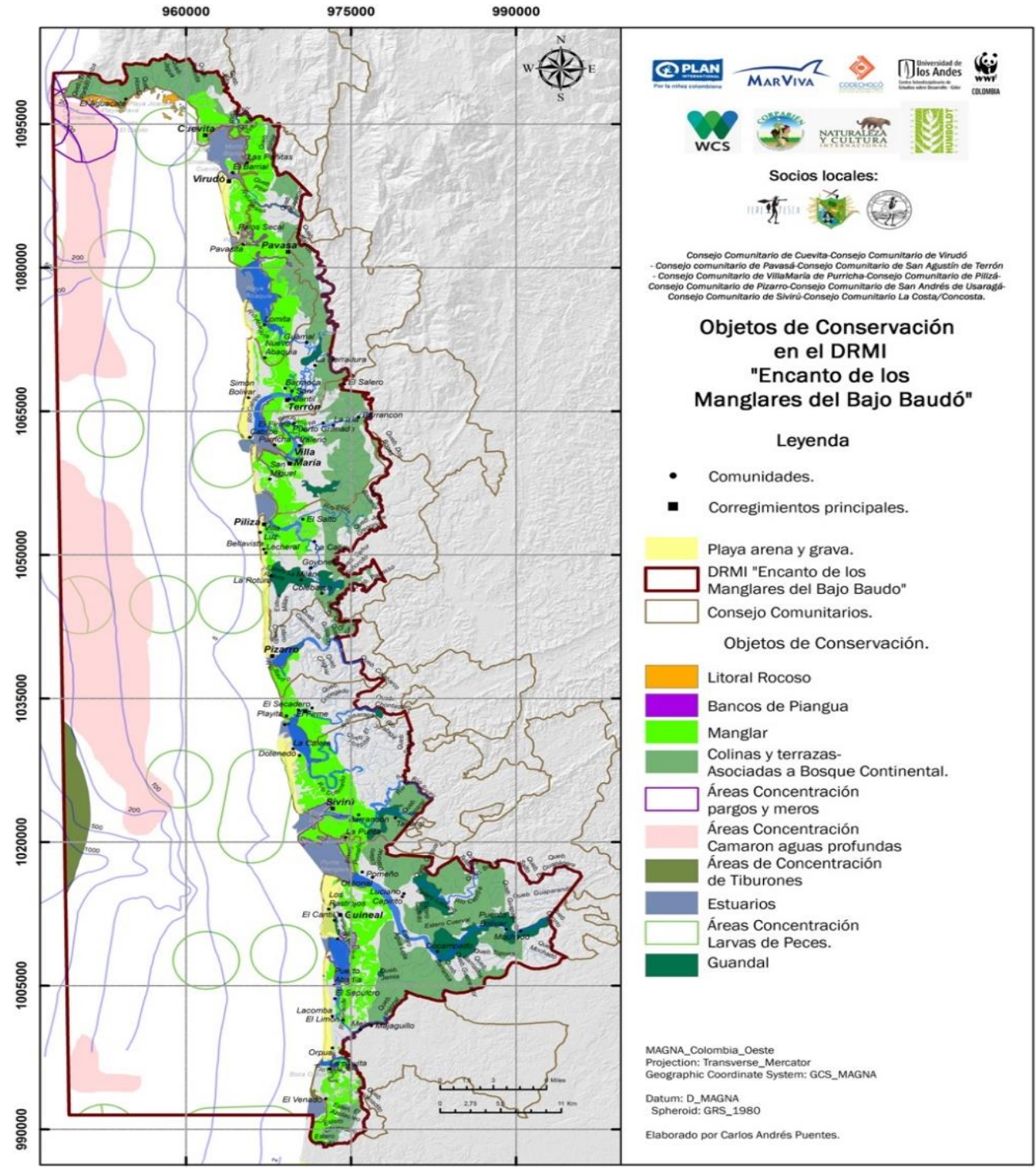

Baudó

Fuente: MarViva

\section{Sivirú en el contexto regional}

Sivirú es un corregimiento de aproximadamente 200 hogares situado en el territorio colectivo afrocolombiano de Sivirú, aproximadamente a una hora en lancha de motor de Pizarro, la cabecera municipal del Bajo Baudó (Figura 2). Las tierras de Sivirú con titulación colectiva cubren cerca de 21.500 hectáreas de bosques de manglar y ríos que desembocan en el océano

Turner, K.L., Idrobo, C.J., Desmarais, A.A., y Peredo, A.M. (2020). Soberanía alimentaria desde el territorio: aprovisionamiento, prácticas cotidianas y el papel de las mujeres afrocolombianas en el mantenimiento de sistemas alimentarios. Jangwa Pana, 20(1), 158-185. doi: https://doi.org/10.21676/16574923.3996 
Pacífico (CODECHOCÓ et al., 2017, p. 181). Con una temperatura promedio de entre 26 y $28^{\circ} \mathrm{C}$, y una precipitación media anual de $6.000 \mathrm{~mm}$, el municipio de Bajo Baudó es una de las áreas más húmedas, boscosas y biológicamente diversas del continente (Ministerio del Trabajo y PNUD, 2013). El 64.7\% de la población de 17.000 habitantes del Bajo Baudó se auto-identifica como afrocolombiana (concentrada en Pizarro, en zonas costeras y estuarinas), y un 32.5\% como pueblos indígenas Emberá (concentrados en las cabeceras de las cuencas hidrográficas). Gracias a la Ley 70 de 1993, se concedió la titulación colectiva de tierra a Sivirú y a otras comunidades afrocolombianas y a la vez que se confirió autoridad a los Consejos Comunitarios para la toma de decisiones (República de Colombia, 1993).

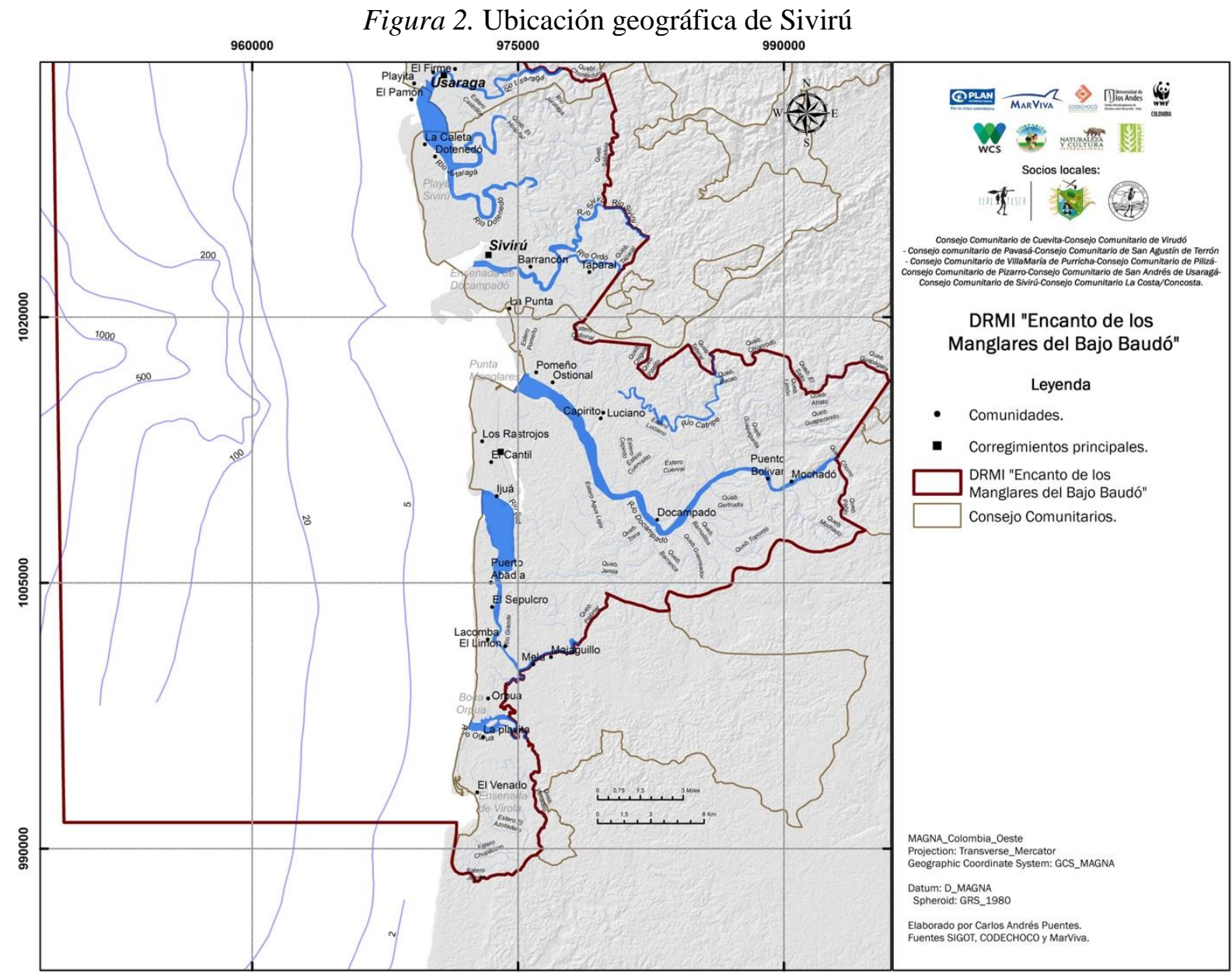

Fuente: MarViva

El Bajo Baudó ha sido profundamente afectado por décadas de conflicto armado y violencia contra la población civil perpetrada por grupos paramilitares y guerrilleros, los cuales persisten a pesar de la implementación de los Acuerdos de Paz de 2016. Los abusos a los derechos humanos van desde asesinatos hasta desplazamiento forzado, reclutamiento infantil, minas terrestres y amenazas (Human Rights Watch, 2017). Por otro lado, el establecimiento de cultivos ilícitos, el tráfico de drogas y la minería ilegal realizados por organizaciones criminales y grupos armados ilegales también se constituyen en focos de violencia y destrucción ecológica. En 2011, más de 5.000 personas fueron violentamente

Turner, K.L., Idrobo, C.J., Desmarais, A.A., y Peredo, A.M. (2020). Soberanía alimentaria desde el territorio: aprovisionamiento, prácticas cotidianas y el papel de las mujeres afrocolombianas en el mantenimiento de sistemas alimentarios. Jangwa Pana, 20(1), 158-185. doi: https://doi.org/10.21676/16574923.3996 
desplazadas en el Bajo Baudó, casi una tercera parte de la población del municipio (Ministerio de Trabajo y PNUD, 2013).

Casi toda la movilidad dentro del municipio y el comercio con el exterior se realiza utilizando pequeñas embarcaciones que se desplazan por río y mar. Más del 55\% de la población nunca ha asistido a una escuela primaria o sólo posee este nivel de estudios, el $71 \%$ tiene electricidad (generalmente seis horas diarias), el 18\% tiene acueducto y casi toda desecha los residuos sólidos en vías fluviales o vertederos improvisados (Ministerio de Trabajo y PNUD, 2013). Por su parte, las telecomunicaciones se limitan a una conexión de internet inalámbrico a la cual los miembros de la comunidad compran el acceso por horas.

En 2017, debido a preocupaciones de la población relacionadas con la pesca industrial, las prácticas de pesca artesanal no selectivas, la deforestación de manglares y la sobreexplotación de especies silvestres, los once Consejos Comunitarios del Bajo Baudó se reunieron para establecer un DRMI al que llamaron el Encanto de los Manglares del Bajo Baudó. Esta es el área marina protegida más grande de Colombia y cubre cerca de 315.000 hectáreas (MarViva, 2018). El DRMI se propone conservar los valores del patrimonio ecológico y cultural en un marco de uso sostenible y desarrollo comunitario. De hecho, cuando realizamos nuestro trabajo de campo, aún estaba en marcha un proceso de planificación para el manejo de esta área que implica la identificación de zonas de uso sostenible, restauración y conservación. En los últimos años, Sivirú y otras comunidades del Bajo Baudó también han decretado cierres voluntarios de pesquerías, incluyendo piangua, además de adherirse a cierres por mandato nacional de camarón y otras especies estuarinas. Es en este contexto histórico a nivel regional que las personas que viven en Sivirú trabajan para abastecerse y mantenerse a sí mismos, a sus familias y a su comunidad.

\section{Panorama de las economías costeras tradicionales y contemporáneas de los afrocolombianos}

Las comunidades afrocolombianas en el Bajo Baudó y el Pacífico colombiano en general dependen en gran medida del aprovisionamiento de recursos naturales, razón por la cual se han mantenido culturas características, prácticas de uso de estos recursos y formas de organización social que mantienen sistemas alimentarios locales diversos y específicos (Asher, 2009; Escobar, 2008; Ministerio de Cultura y Fundación ACUA, 2015, 2016; Oslender, 2016). Sin embargo, un informe del Ministerio de Trabajo y el PNUD (2013, p. 13) describe la economía del Bajo Baudó de esta manera:

La agroforestería y la pesca para el autoabastecimiento llevadas a cabo por pequeños propietarios son la base económica del municipio, lo que en esta región del país es sinónimo de pobreza y miseria debido a la baja competitividad de las empresas agrícolas manejadas bajo este enfoque.

Aunque miembros de la comunidad y líderes locales identifican distintas falencias en su bienestar, la mayoría de ellos no se describen a sí mismos como si vivieran en la "pobreza y miseria", tampoco ven la producción de alimentos a pequeña escala como la fuente de sus problemas. Más allá de esto, muchos se sienten individual y colectivamente orgullosos de sus medios de vida, sus prácticas de aprovisionamiento y su identidad cultural particular.

Turner, K.L., Idrobo, C.J., Desmarais, A.A., y Peredo, A.M. (2020). Soberanía alimentaria desde el territorio: aprovisionamiento, prácticas cotidianas y el papel de las mujeres afrocolombianas en el mantenimiento de sistemas alimentarios. Jangwa Pana, 20(1), 158-185. doi: https://doi.org/10.21676/16574923.3996 
A pesar de los cambios ocurridos en las últimas décadas, Sivirú mantiene una economía muy diversa en la que la agricultura a pequeña escala, la pesca artesanal y la recolección de alimentos silvestres persisten como actividades centrales. Las prácticas locales de aprovisionamiento, fundamentales para el mantenimiento de los paisajes alimentarios de los hogares en Sivirú, se basan en ecosistemas diversos y redes sociales (Figura 3). En el pasado, era muy común que las familias vivieran en parcelas agrícolas ubicadas tierra adentro y se reunieran solamente para celebraciones y eventos especiales en lo que hoy son pueblos y asentamientos. No obstante, durante las últimas tres o cuatro décadas, con el fin de acceder a la educación y otros servicios y debido a la creciente inseguridad generada por la violencia, las familias comenzaron a establecerse permanentemente en el casco urbano de Sivirú. Poco a poco, los miembros de la comunidad adaptaron sus prácticas de aprovisionamiento y hoy en día, mientras la producción agrícola continúa en parcelas ancestrales, las actividades relacionadas con la pesca se han trasladado de ríos y estuarios hacia la costa y la caza ha disminuido. Por otro lado, el cultivo en huertos caseros también se ha vuelto cada vez más importante para las familias que ya no viven cerca de sus campos de cultivo.

Figura 3. Paisajes alimentarios en Sivirú

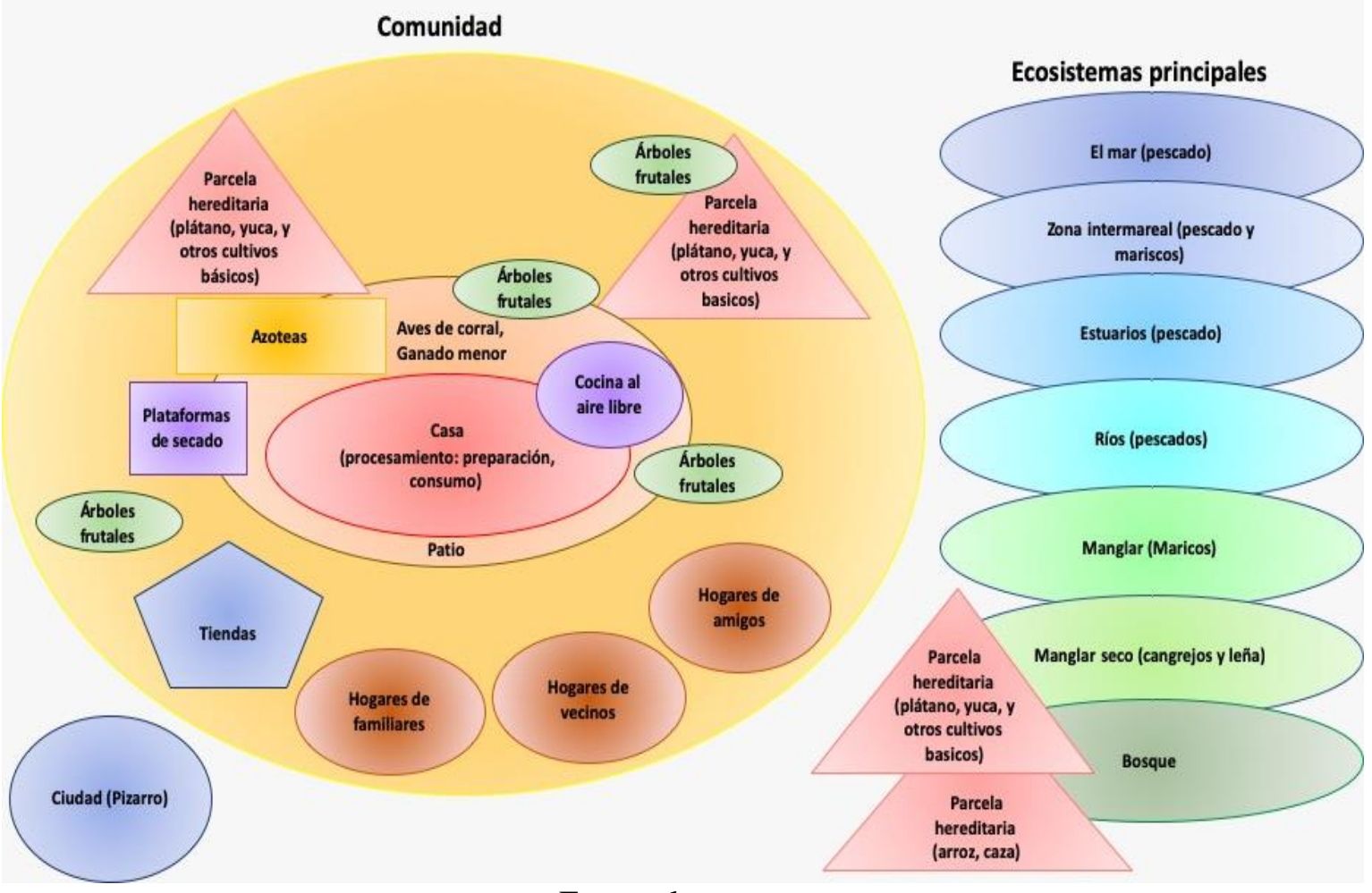

Fuente: los autores

La mayoría de los hogares se dedican a la pesca, la agricultura y la cosecha del manglar para proveer a sus familias. Además de la venta de pescado, la producción comercial de coco se ha incorporado al sistema de producción agrícola recientemente, mientras que el trabajo remunerado y las remesas también han incrementado. Por otra parte, en este momento los alimentos producidos afuera del territorio también están disponibles. Entre estos se incluyen huevos, carne congelada, lácteos, frutas y verduras, aceite de cocina, azúcar, sal, harina de 
trigo, harina de maíz, arroz, alcohol, bebidas azucaradas, galletas, papas fritas, dulces y otras golosinas.

En los años ochenta, antes del uso generalizado de motores fuera de borda, los hogares eran prácticamente autosuficientes en cuanto a la producción de alimentos. El intercambio y regalo de alimentos en las redes familiares y amigos eran prácticas comunes de aprovisionamiento que aún persisten aunque en menor medida. Según explica un informante clave, las personas mayores otorgan un gran valor a la producción de comida para alimentar a la familia: "Su felicidad era tener mucho plátano y papachina (Colocasia esculenta) en la finca... La mayor preocupación era tener a la familia bien alimentada". Al regresar de la finca, todavía es costumbre compartir la cosecha. Como Julia explicó: "Cuando traemos mucho plátano de [nuestra parcela] río arriba, vamos donde cada uno de nuestros familiares y les damos unos buenos plátanos que durarán unos días... es lo mismo con el pescado." Un pescador comentó: "si voy a pescar y el vecino no tiene nada para comer, lo regalo pescado a mi vecino. Así es como nosotros nos apoyamos aquí... es la costumbre."

Ahora que el dinero se usa con más frecuencia y se necesita para varios gastos, algunos alimentos también se intercambian a través de transacciones monetarias. Sin embargo, es común que esto se haga sin fines de lucro. Como líder comunitario e informante clave, Dainer señala:

Aquí usted casi no compra pescado. Es normal que alguien le diga que venga y coja un pescado, o usted puede preguntar para comprar una libra. Ellos le venden una libra, pero realmente usted se lleva a la casa dos o tres... aquí también vendemos por tradición... La gente va con sus productos, por ejemplo el marañón (Syzygium malaccense) o dulces pequeños como cocadas para intentar ganar algo de dinero y comprar lo que necesitan, pero la forma en que lo venden es como si fuera un regalo.

Las personas mencionan la importancia de estas redes comunitarias en la dieta familiar, especialmente en tiempos de escasez. Una mujer afirma: "Yo me acuerdo que mi mamá iba donde el vecino, cualquiera que tuviera algo y preguntaba por pescado... Ella conseguía pescado para comer o huevos, a veces los compraba, pero sin preocuparse por cuántos cogió o si debía devolverlos." El lenguaje de compartir alimentos es común y refleja esa comprensión de reciprocidad que está inmersa en el intercambio.

El intercambio colectivo de trabajo es otro sistema de apoyo mutuo que todavía se practica en Sivirú y otras comunidades afrocolombianas en el Chocó. Mano cambiada, a la que también se refieren en Sivirú por el término colonial minga, es un acuerdo de intercambio utilizado para la agricultura y otras labores. Como explicó un miembro de la comunidad: "Usted le dice a sus vecinos -el sábado necesito que me ayude con este trabajo-, usted les da comida y ellos vienen y le ayudan... y cuando ellos necesitan ayuda, es lo mismo." A pesar de que ha disminuido la frecuencia de estas prácticas de trabajo compartido, de acuerdo con los habitantes de Sivirú, aún se mantienen prácticas sociales y culturales que son importantes para la comunidad.

\section{Aprovisionamiento de alimentos y género en Sivirú}

Turner, K.L., Idrobo, C.J., Desmarais, A.A., y Peredo, A.M. (2020). Soberanía alimentaria desde el territorio: aprovisionamiento, prácticas cotidianas y el papel de las mujeres afrocolombianas en el mantenimiento de sistemas alimentarios. Jangwa Pana, 20(1), 158-185. doi: https://doi.org/10.21676/16574923.3996 
Muchas actividades de aprovisionamiento tienen dinámicas de género y de clase particulares, lo que influye en el tiempo, lugar de cosecha y disponibilidad de alimentos y otros recursos en el hogar. Aunque se reconocen ampliamente ciertos roles de género, responsabilidades y especializaciones flexibles, durante las reuniones y talleres comunitarios, los hombres frecuentemente se presentan a sí mismos como pescadores y/o agricultores, mientras que la mayoría de las mujeres se refieren a ellas mismas simplemente como amas de casa y, ocasionalmente, como piangüeras.

Particularmente, las contribuciones de las mujeres a la provisión de alimentos en el hogar están determinadas por su responsabilidad sobre el espacio doméstico y las correspondientes actividades reproductivas relacionadas con la preparación de comidas, la lavandería, la limpieza y el cuidado infantil y familiar. Por ejemplo, la planeación y preparación de comidas para el hogar (y algunas veces para la familia extendida) sucede dos a tres veces al día y normalmente requiere de una a dos horas por comida. Con estas actividades regulares pero intermitentes, la mayoría de las esferas de actividad de las mujeres ocurren en cercanías de su casa. Así, las mujeres son las encargadas del manejo y la toma de decisiones en el cultivo de huertos caseros y la recolección de mariscos, contribuyen a la producción agrícola y participan en distintas actividades productivas secundarias (Figura 4), mientras que los hombres se inclinan por sobresalir en perfiles altos de sectores pesqueros y agrícolas con productos orientados al comercio, como por ejemplo el coco y el pescado.

Figura 4. Actividades económicas desagregadas de acuerdo a género de los integrantes del hogar con más de 13 años

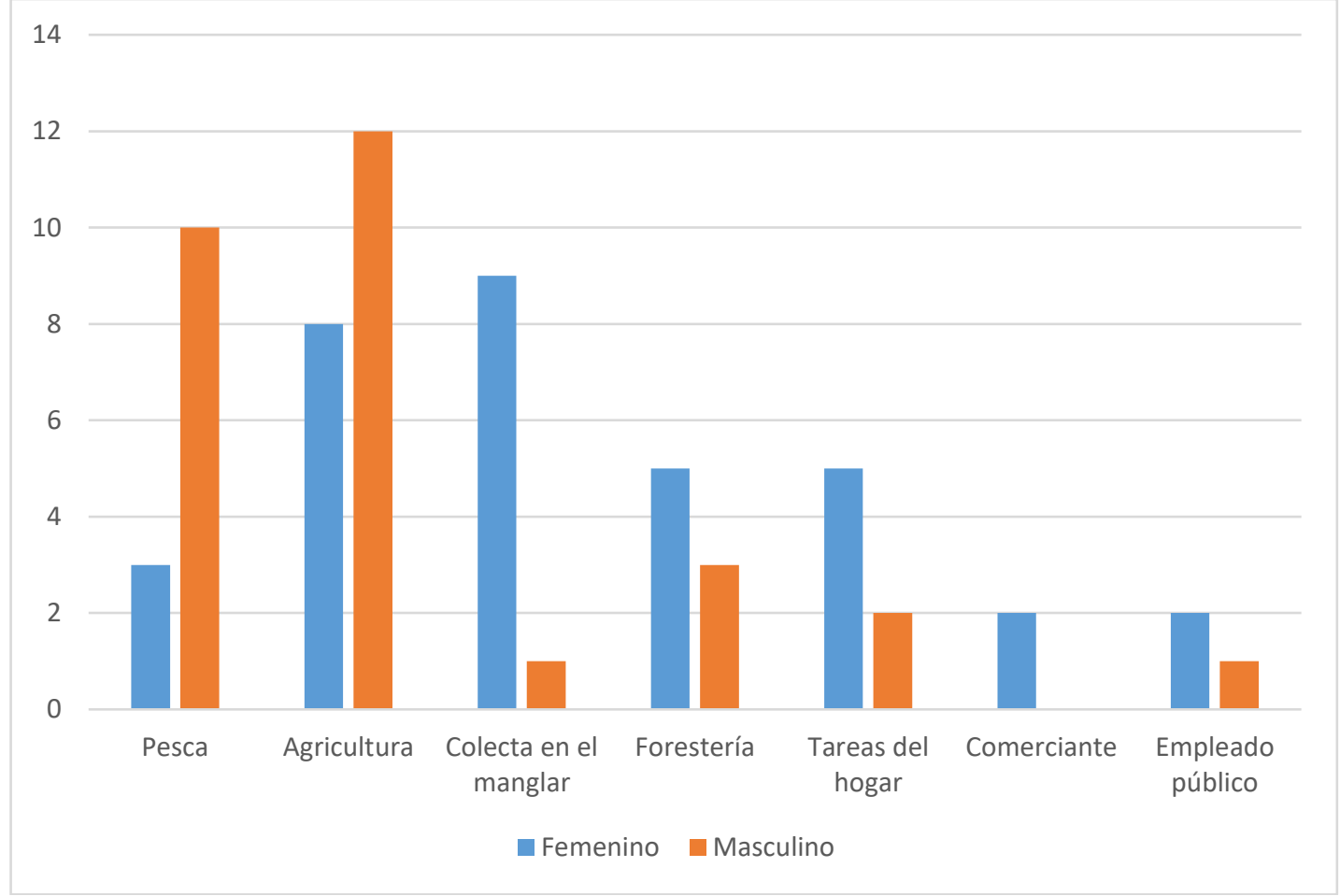

Fuente: Datos encuesta Cider-MarViva

Turner, K.L., Idrobo, C.J., Desmarais, A.A., y Peredo, A.M. (2020). Soberanía alimentaria desde el territorio: aprovisionamiento, prácticas cotidianas y el papel de las mujeres afrocolombianas en el mantenimiento de sistemas alimentarios. Jangwa Pana, 20(1), 158-185. doi: https://doi.org/10.21676/16574923.3996 
El rebusque se refiere a aquellos medios de vida basados en múltiples fuentes de ingresos que a menudo se clasifican como "precarios" e "informales". Concretamente, en Sivirú las personas hablan de este rebusque con relación a la idea de "juntar" una estrategia de subsistencia que incluye el acceso al dinero. La producción en huertos caseros y pianguar son dos dominios importantes del sistema alimentario local en los que las mujeres se involucran como parte de sus actividades de aprovisionamiento o de rebusque.

Es usual que en el hogar no se compartan las finanzas entre hombres y mujeres, mucho menos se tenga un acceso equitativo al dinero. Aunque los hombres, quienes a menudo obtienen efectivo más facilmente a través de la pesca y agricultura comercial o el trabajo remunerado, pueden proveer un sustento familiar que administra la mujer jefe de hogar, esto no necesariamente es suficiente para satisfacer las necesidades de la casa o cubrir los gastos personales de las mujeres. Es por esta razón que hasta cierto punto, el rebusque se considera importante para todas las mujeres, sin embargo, su necesidad depende en gran medida de las condiciones individuales. Para las mujeres cabeza de hogar, el aprovisionamiento de la casa es básico para sobrevivir, mientras que las mujeres que viven en familias más acomodadas o que tienen ingresos regulares, pueden no tener las mismas necesidades. Como explica Francia, una piangüera ocasional de mediana edad con esposo e hijos: "Las mujeres nos la rebuscamos porque no nos gusta depender de nuestros maridos."

A pesar de esto, las mujeres en Sivirú tienen opciones limitadas para obtener ingresos, especialmente si no migran a Pizarro u otros centros urbanos en Colombia. En consecuencia, la piangua es considerada como uno de los pocos recursos comerciales a los que tienen acceso las mujeres. De la misma forma, algunas mujeres también venden o intercambian productos de sus huertos caseros especialmente hierbas aromáticas, huevos y aves de corral, mientras que otras producen y venden viche (ron de caña de azúcar). Hay también mujeres que lavan ropa o mantienen pequeñas tiendas y unas pocas tienen empleo en el sector de la educación o la salud.

Sara Luz, una madre soltera que vive con cuatro de sus siete hijos, distribuye su tiempo entre la huerta casera, el cuidado de ganado menor, la recolección de piangua y la producción de arroz y otros alimentos básicos. Ella vende sus pollos, huevos, hierbas y piangua, a la vez que cultiva productos para alimentar a su familia. En el caso contrario, las mujeres más acomodadas que tienen amplias redes de apoyo son más propensas a mantener un huerto casero casi exclusivamente para uso doméstico y cosechar ocasionalmente la piangua si se quiere preparar un plato de mariscos o para venderlos y obtener dinero extra para ellas o para su hogar. Así, la clase social también influye sobre el rebusque de las mujeres y su participación en diferentes ámbitos del sistema alimentario local, incluso dentro de un espectro de desigualdad relativamente estrecho.

\section{La agricultura y la producción en huertos caseros}

Los alimentos de las parcelas agrícolas contribuyen de forma importante a la dieta del hogar y a la provisión de productos frescos y saludables que son valorados por la familia, que se comen y se comparten con orgullo dentro de la comunidad. La mayoría de los hogares mantienen parcelas de 1 a 3 hectáreas río arriba, aproximadamente a media hora en lancha a motor desde Sivirú. En estos sistemas, se tiene en cuenta la frecuencia de producción y su 
orden de importancia. El arroz se posiciona como el cultivo que más sobresale en estas parcelas, seguido del banano y el plátano, los tubérculos (Ej. papachina; yuca, Manihot sculenta), la caña de azúcar, el coco y el maíz, además de frutas como el lulo (Solanum sessiliflorum), piña (Ananas comosus), guanábana (Annona muricata) y guayaba (Psidium guajava). El trabajo en las parcelas agrícolas también facilita actividades como la caza menor y la recolección de alimentos silvestres. En este contexto, tanto hombres como mujeres terminan involucrándose en la producción agrícola. Las mujeres en particular contribuyen principalmente con labores de siembra y cosecha, y preparan comidas durante estas actividades. En estas temporadas las familias grandes se colaboran entre sí a través de la figura de mano cambiada.

Las mujeres también son las responsables de la producción en huertos caseros. Si tenemos en cuenta la división de labores en el hogar, mientras que los hombres pueden contribuir con la construcción de infraestructura y con el trabajo pesado, los huertos caseros son considerados como el ámbito de la mujer. Estos huertos son característicos de casi todos los sistemas alimentarios de los hogares que se encuestaron, aunque su complejidad e importancia dietaria varía dependiendo de la tierra y el tiempo disponibles, la importancia de otras actividades para el aprovisionamiento y el interés personal. Los huertos caseros incluyen cuatro espacios y prácticas diferentes: las azoteas (huertos elevados), los árboles frutales, la producción de alimentos básicos a pequeña escala y el cuidado de ganado menor. En ocasiones, las mujeres se apoyan mutuamente en estas actividades prestando y pidiendo prestado productos, plántulas y semillas. Sin embargo, como una mujer enfatiza, tener su propio huerto es fundamental: "Si por casualidad usted necesita algo, va donde su vecina y ella se lo da, pero solo una o dos veces; es importante que cada uno tenga su propia azotea."

\section{Azoteas}

El cultivo en azoteas [pequeños huertos elevados (Figura 5)] es una práctica ancestral que se transmite matrilinealmente y permanece como una característica icónica de los sistemas alimentarios del Pacifico afrocolombiano (Arroyo, Camacho, Leyton \& González 2001). Juliana explica cómo aprendió a cultivar las azoteas gracias a las mujeres de su familia: "Llevo mucho tiempo en esto, prácticamente desde que era una niña... Yo observaba a mi mamá, a mi abuela, a mi tía. Luego, cuando ya era adulta y realmente una experta, tuve la idea de hacer esto también."

Por tradición, las azoteas son establecidas sobre canoas que ya no son aptas para la navegación, aunque algunas también están hechas de bases de madera y se complementan con macetas improvisadas como cubetas viejas, ollas y otros recipientes disponibles. Estas estructuras se levantan a $1.5 \mathrm{~m}$ o más sobre el suelo en soportes de madera. De igual forma, una tierra especial llamada tierra de hormigas recolectada en hormigueros, del compost o capote del suelo, se utiliza para llenar la azotea. La producción en las azoteas, y en general en los huertos caseros, es casi siempre orgánica. De hecho, las mujeres mencionan este aspecto con orgullo preocupándose también por los impactos a la salud derivados del uso de químicos.

Turner, K.L., Idrobo, C.J., Desmarais, A.A., y Peredo, A.M. (2020). Soberanía alimentaria desde el territorio: aprovisionamiento, prácticas cotidianas y el papel de las mujeres afrocolombianas en el mantenimiento de sistemas alimentarios. Jangwa Pana, 20(1), 158-185. doi: https://doi.org/10.21676/16574923.3996 
Figura 5. Azoteas con base de madera rodeadas de papaya, coco y otros árboles frutales

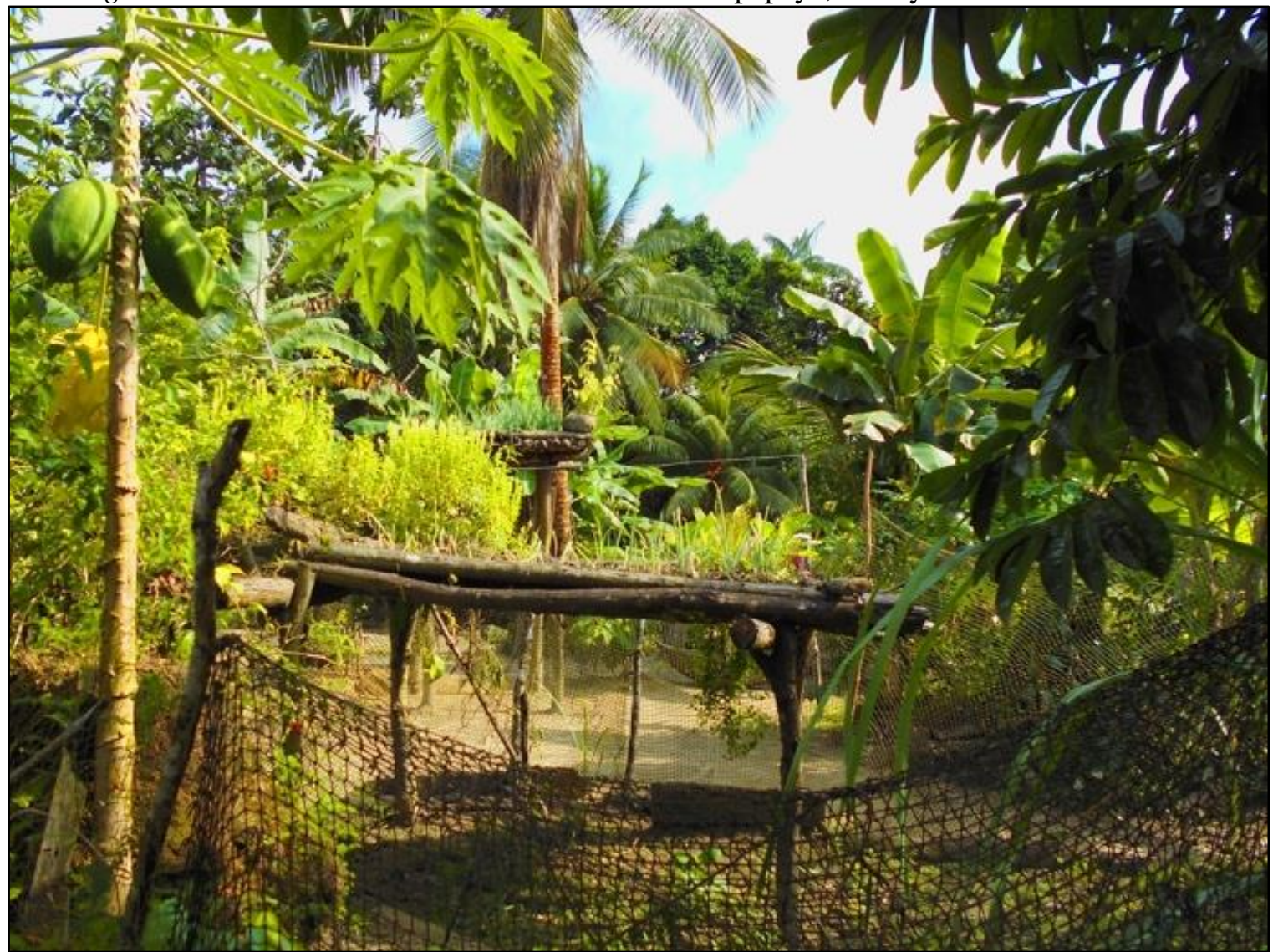

Las azoteas se ubican cerca de la casa y se siembran con verduras (E.g., cebolla, cebolla larga, tomate, repollo, calabaza, pimentón, ajíes, espinaca blanca) y muchas otras hierbas que son importantes para la gastronomía local. La categoría de hierbas conocidas como "hierbas de la azotea" incluye la albahaca [Ocimum basilicum, con dos variedades morada y blanca utilizadas más como medicina que como condimento], cilantro cimarrón (Eryngium foetidum), orégano (Origanum vulgare), poleo (Mentha pulegium), hierbabuena (Mentha spicata), entre otras]. A pesar de que en Colombia y en Sivirú se ha vuelto cada vez más común el uso de condimentos artificiales e industriales como los cubos Maggi, muchas personas valoran el uso de hierbas de la azotea en su cocina, señalando que éstas proporcionan un sabor especial y que son más sanas. Juliana explica: "Es el sabor que tenemos. Usted ve un sancocho y con estas hierbas que uno cultiva ¡Ah, la comida es muy deliciosa!"

Muchas plantas cultivadas también se usan como medicinas tradicionales y se respetan dentro de la comunidad. De igual forma, los árboles frutales crecen en jardines para ofrecer alimento y sombra, junto con algunas plantas ornamentales como el algodón y la hoja blanca (Calathea lutea), cuyas hojas se usan para envolver alimentos en la cocina. El mantenimiento y la replantación de la azotea se realiza cada pocos meses dependiendo del ciclo de vida de la plantas.

Turner, K.L., Idrobo, C.J., Desmarais, A.A., y Peredo, A.M. (2020). Soberanía alimentaria desde el territorio: aprovisionamiento, prácticas cotidianas y el papel de las mujeres afrocolombianas en el mantenimiento de sistemas alimentarios. Jangwa Pana, 20(1), 158-185. doi: https://doi.org/10.21676/16574923.3996 


\section{Cultivo de árboles frutales}

Una característica impactante de Sivirú y otras comunidades del Bajo Baudó es que el espacio físico de la comunidad es un paisaje comestible. Con excepción de unas cuantas especies ornamentales, casi todos los árboles y plantas son frutos comestibles: aguacate (Persea americana), banano (Musa sapientum), borojó (Alibertia patinoi), árbol del pan (Artocarpus altilis), cacao (Theobroma cacao), coco (Cocos nucifera), chirimoya (Annona cherimola), guayaba (Psidium guajava), guama (Inga edulis), limón (Citrus spp.), lulo, mango (Mangifera indica), papaya (Carica papaya), plátano (Musa x paradisiaca), naranja (Citrus sinensis), guanábana, marañón y otros. Las semillas suelen brotar espontáneamente sobre desperdicios, se trasplantan y se cuidan para cuando vayan a ser cultivadas. Por otro lado, la comunidad también es consciente sobre la propiedad del hogar y los derechos sobre la cosecha de árboles frutales y así saben cuáles árboles pertenecen a quién. La fruta se recolecta y se come en el hogar y algunas veces, los hijos de propietarios la venden o la regalan en la comunidad.

\section{Producción de alimentos básicos a pequeña escala}

En la comunidad algunos hogares también mantienen pequeñas parcelas $\left(\mathrm{Ej} .5-15 \mathrm{~m}^{3}\right)$ que no necesariamente están dentro o cerca de sus patios. Estas parcelas frecuentemente se heredan de otros miembros de la familia y se utilizan para establecer pequeños cultivos de alimentos básicos como plátano, banano, yuca y papachina. En general, las mujeres son las encargadas de manejar estas parcelas proporcionando una fuente de alimento importante, aunque complementaria, en el caso de no poder llegar a zonas de cultivo más grandes en el río, de necesitar comida a corto plazo o si la familia no posee estas parcelas agrícolas.

\section{Cuidado de ganado menor}

Las personas en Sivirú coinciden en que ahora existe una menor producción de ganado menor debido a la mayor disponibilidad de carne y huevos para comprar y a los cambios en la vida comunitaria. A pesar de esto, la mayoría de los hogares continúan la crianza de pollos y patos con el fin de obtener carne, huevos e ingresos. Las aves de corral son propiedad de las mujeres, quienes son responsables de su manejo y cuidado, a menudo con la ayuda de los más pequeños. Estas aves se alimentan de maíz y restos domésticos, y pueden estar en grupos de 5 a 10 en promedio, o en ocasiones de 15 a 20 aves adultas dependiendo del hogar y de la época del año. Muchas familias prefieren criar pollos para vender en lugar de comer los huevos y esto representa una fuente importante de ingreso para el hogar. En ese caso, se pueden vender pollos a unos $\$ 25.000 \mathrm{COP}$, cerca del equivalente de un jornal en otras actividades (ver abajo). Por otro lado, el ganado también constituye una fuente de ingreso y proteínas en ciertos momentos dependiendo de las necesidades del hogar.

\section{Subsistema de recolección de mariscos}

La recolección de mariscos se considera un trabajo muy difícil y peligroso en el que las mujeres realizan la mayor parte de las actividades de recolección de alimentos silvestres. Libia, una informante clave, reflexiona: "Los hombres dicen 'No voy a ir [a pianguar]' porque no es de hombres, es oficio de mujeres." No obstante, algunos hombres pianguan ocasionalmente junto con mujeres de su familia, aunque esto es poco común y no se considera una actividad de sustento a largo plazo. La recolección de piangua (Anadara tuberculosa) es la actividad principal aunque hay otros recursos [como el piacuil (Littorina spp.) y varias

Turner, K.L., Idrobo, C.J., Desmarais, A.A., y Peredo, A.M. (2020). Soberanía alimentaria desde el territorio: aprovisionamiento, prácticas cotidianas y el papel de las mujeres afrocolombianas en el mantenimiento de sistemas alimentarios. Jangwa Pana, 20(1), 158-185. doi: https://doi.org/10.21676/16574923.3996 
especies de cangrejos (tasquero, Goniopsis sp; meón, Gecarcinus quadratus; jaiba, Callinectes arcuatus)] que son colectados en conjunto con la piangua, son estacionales (como el cangrejo azul, Cardisoma crassum) o no tan frecuentes (Figura 6). Es difícil determinar el número exacto de mujeres y hogares que se dedican a la recolección de la piangua en Sivirú a pesar de que existe todo un espectro de participación y dependencia de esta práctica de aprovisionamiento. De hecho, el cincuenta y cinco por ciento de los hogares encuestados $(n=17)$ reporta que cosechan piangua. Un comprador de este molusco estima que actualmente compra a 20-25 personas, otro informa que compra regularmente a diez, lo que sugiere que alrededor de 30 personas participan con frecuencia en el comercio de la piangua, aunque muchas mujeres pueden cosecharlas exclusivamente o por lo menos en gran medida para el consumo de los hogares. Los informantes clave estimaron que de cuatro a ocho mujeres, la mayoría de las cuales son cabeza de hogar y madres solteras, dependen de la venta de piangua como fuente principal de ingresos. Las mujeres con mayor dependencia del comercio de piangua la recolectan gran parte de la semana. Libia, cuyas actividades de cosecha se encuentran en la mitad del espectro, va una o dos veces al mes y a veces sale por varios días seguidos asignando casi un tercio de su cosecha al consumo familiar (10 a 12 docenas de piangua) y el resto a la venta (20 a 30 docenas). Otras mujeres cosechan solamente cuando quieren cocinar lo que recolectaron.

Los volúmenes de cosecha varían considerablemente según la temporada, la marea y la habilidad de la recolectora. Durante la marea de quiebra, las cosechas son más grandes y los viajes de recolección duran todo el día (desde el amanecer hasta las 4:30/5pm), mientras que en la marea de puja, la captura es menor y los viajes de recolección son más cortos (e.g., 8am a 2pm). Las recolectoras ocasionales normalmente concentran sus esfuerzos durante la marea de quiebra, mientras que las mujeres que son más dependientes de este ingreso cosechan todo el mes. Sin embargo, en los meses de invierno y debido a los cambios en la salinidad del agua, la piangua se entierra más en el lodo y no es posible cosecharla.

A mediados de la década de los 2000, Sivirú estableció un cierre estacional con el fin de mejorar la salud poblacional de distintas especies de mariscos. A pesar de que al principio existió incertidumbre con respecto a la efectividad de esta medida, hoy en día las piangüeras la perciben como un factor que contribuyó al mejoramiento de sus cosechas. Sin embargo, debido a la falta de un monitoreo consistente, es imposible saber con certeza cuáles son los actuales niveles de captura o cómo se comparan estos con las capturas pasadas. Las recolectoras mayores comentan que en el pasado había una gran abundancia a la que siguieron períodos de disminuciones, y ahora tal vez, una temporada de recuperación moderada. 
Figura 6. Especies colectadas en ecosistemas de manglar clasificados de acuerdo a su importancia para los hogares

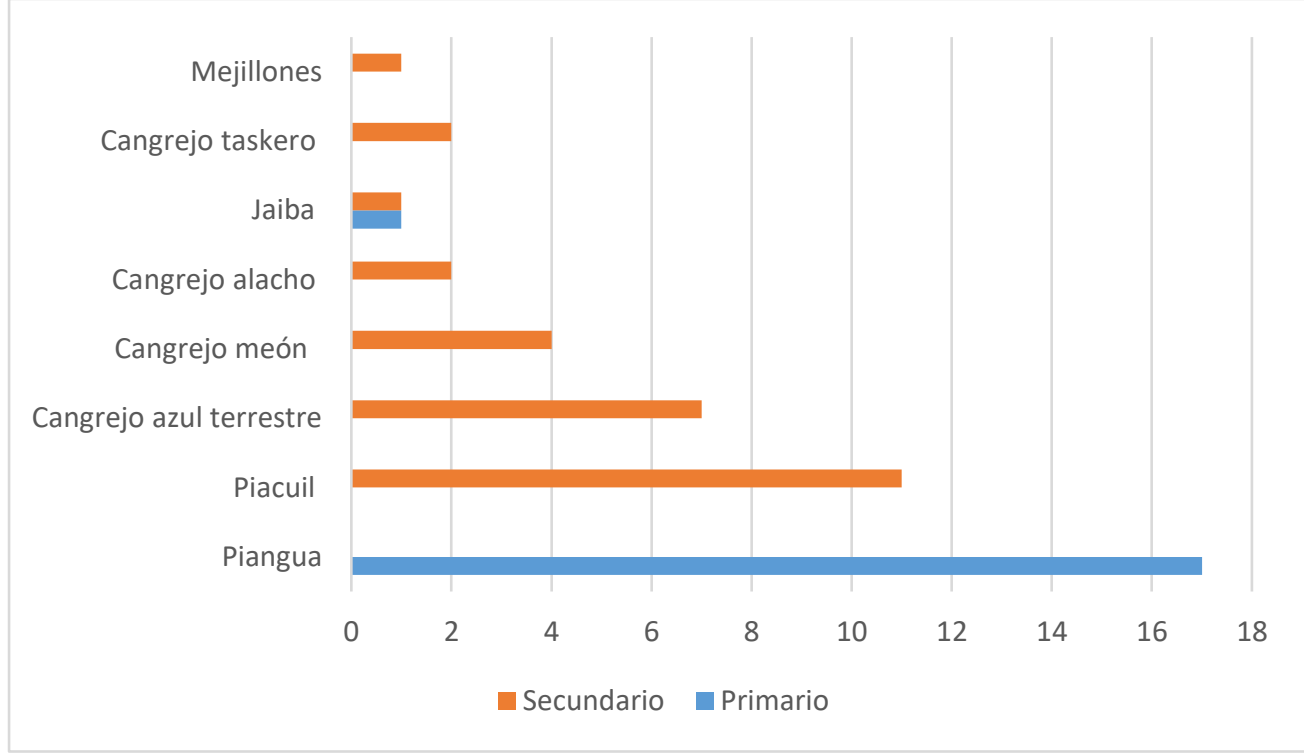

Fuente: Datos encuesta Cider-MarViva

Para una recolectora experimentada una buena cosecha abarca de 50 a 60 docenas de piangua con un peso de $1.5-2 \mathrm{~kg}$ con concha (unos 30.000-44.000 COP). Las menos experimentadas reportan capturas de entre $15-20$ docenas (entre $0.5-1 \mathrm{~kg}$ ). En el transcurso de esta investigación, lo usual para recolectoras experimentadas fue una cosecha de 30 a 40 docenas por día (con un peso aproximado de $1-1.5 \mathrm{~kg}$ sin concha). Para tener un punto de referencia, el valor de un jornal para un hombre agricultor en la comunidad es de 30.000 COP. Por otro lado, hace varias décadas, cuando apenas comenzaba el comercio de la piangua, compradores de Ecuador podían comprar hasta 6000 docenas de piangua por semana y pagaban entre 1.200 y 1.500 COP por docena. En 2015, este negocio cambió al mercado nacional, haciendo que los comerciantes de Quibdó, y ocasionalmente aquellos de otras zonas del país, comiencen a comprar piangua con concha a $22.000 \mathrm{COP} / \mathrm{kg}$. Cuando las mareas son favorables, un comprador importante en Sivirú puede conseguir regularmente entre 60-70kg diarios, si son menos favorables, entre 10-15kg diarios. Este comprador paga a alguien en Sivirú para que recolecte y envíe el producto a su pescadería donde revende la piangua a restaurantes y consumidores locales por $40.000 \mathrm{COP} / \mathrm{kg}$.

De igual forma, las mujeres comercian con la piangua a nivel local vendiéndola a otros hogares (1.200 COP/docena con concha) y utilizándola para hacer regalos y trueque. Para mujeres y hogares de escasos recursos, regalar piangua de vez en cuando a los vecinos les permite mantener relaciones sociales de reciprocidad. Una piangüera explica: "Yo comparto con mi mamá, mi suegra y los vecinos... Hay momentos en que uno le da piangua a los vecinos." Otra piangüera menciona cómo en el pasado las mujeres reservaban la piangua para poder intercambiarla por otros alimentos: "Antes, cuando el dinero era muy difícil, antes de ir [a pianguar] las personas arreglaban y decían: 'Vecino, voy a conseguir piangua, deme esto a cambio de la piangua que voy a traer'." Cuando se indagó sobre la importancia relativa de los usos de la piangua en las encuestas de los hogares, se destacó el consumo familiar seguida

Turner, K.L., Idrobo, C.J., Desmarais, A.A., y Peredo, A.M. (2020). Soberanía alimentaria desde el territorio: aprovisionamiento, prácticas cotidianas y el papel de las mujeres afrocolombianas en el mantenimiento de sistemas alimentarios. Jangwa Pana, 20(1), 158-185. doi: https://doi.org/10.21676/16574923.3996 
del comercio local que incluye la venta, el regalo y el intercambio recíproco, y por último, el comercio extra-local.

Generalmente, las mujeres van juntas a cosechar en grupos pequeños de 4 a 5 personas, llegando a las zonas de cosecha en canoa o juntando dinero para la gasolina de una lancha a motor. Ellas van juntas no sólo por razones económicas, sino también por la ayuda mutua que pueden tener en caso de accidente, por compañía, para enseñar a las piangüeras nuevas y jóvenes, o como una medida de seguridad si se encuentran con grupos armados. Mariela explica: "[Ahora] estoy asustada... usted sabe que a veces hay grupos armados y entonces a uno le da miedo ir solo."

Las mujeres entran al manglar con pantalones y camisa de manga larga, pero sin zapatos o guantes (Figura 7). En vista del reto físico que supone pasar sobre y debajo de los zancos del manglar, caminar y atascarse en el barro muchas veces hasta la cintura, las piangüeras llevan lo menos posible, generalmente sólo un balde para recolectar la piangua. Para hacer esto, se introduce la mano y la muñeca en el barro suave y arenoso alrededor de los zancos del manglar. Aquellas que realizan esta actividad dicen llegar a sus casas agotadas, hambrientas y deshidratadas, con dolores de cabeza y de espalda, y sus dedos adoloridos y desgastados. Estas se consideran consecuencias apenas normales y esperadas de recolectar piangua. Las mujeres también pueden encontrar riesgos más graves, como el pejesapo (Pseudopimelodus zungaro) -una especie de bagre con espinas pectorales y dorsales venenosas que vive en el lodo- y serpientes venenosas. A menudo, ellas reciben picaduras de este bagre, lo que resulta en lesiones dolorosas y persistentes que incluyen hinchazón permanente. Cuando regresan a la playa, lavan lo que capturan en aguas poco profundas y luego van a sus casas a preparar comidas familiares y a alistar la piangua para vender.

Figura 7. Mujeres colectando piangua en el manglar

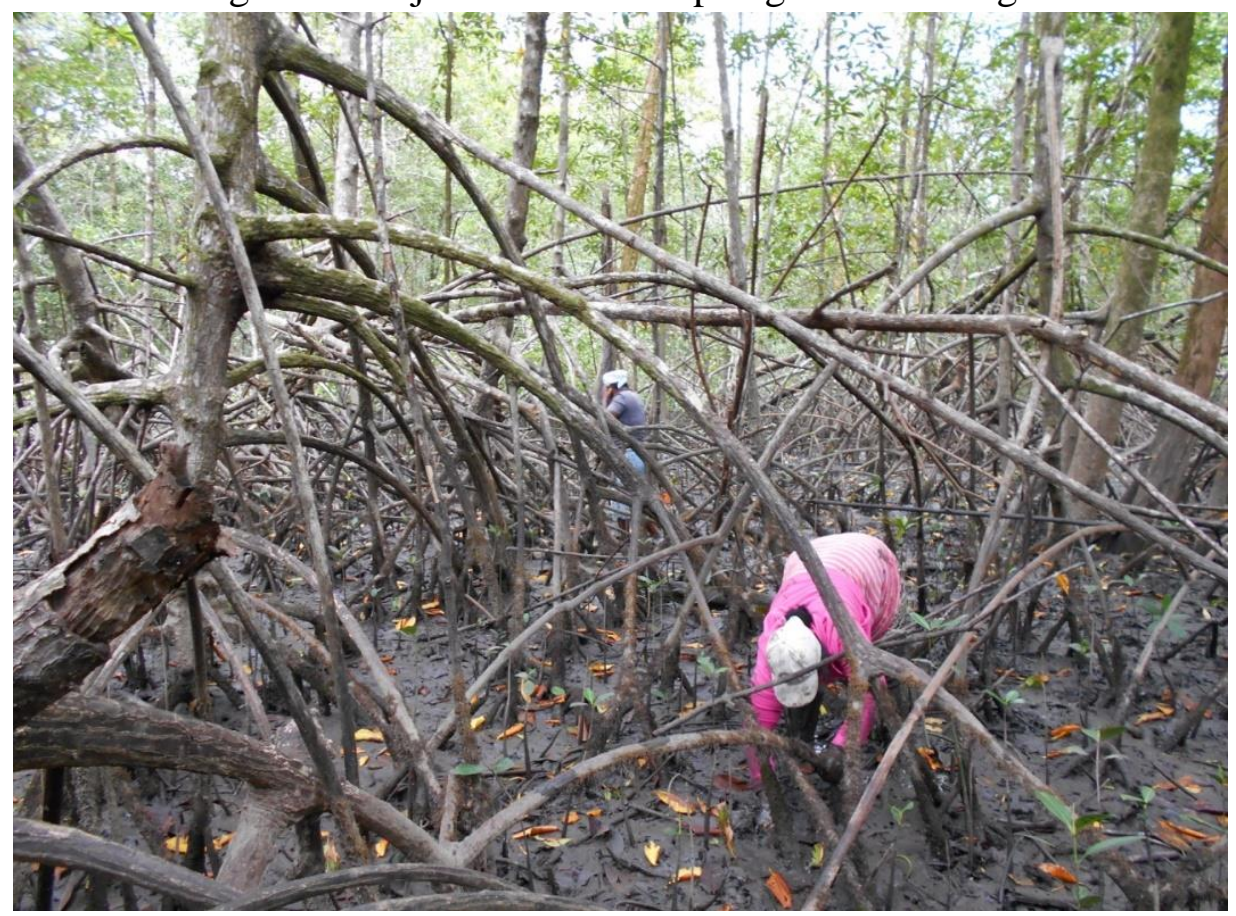

Turner, K.L., Idrobo, C.J., Desmarais, A.A., y Peredo, A.M. (2020). Soberanía alimentaria desde el territorio: aprovisionamiento, prácticas cotidianas y el papel de las mujeres afrocolombianas en el mantenimiento de sistemas alimentarios. Jangwa Pana, 20(1), 158-185. doi: https://doi.org/10.21676/16574923.3996 
Otros mariscos son recolectados en cantidades más pequeñas para el consumo del hogar o por encargo. Almejas, caracoles, cangrejos y otras especies sobresalen no sólo por ser alimentos ricos en nutrientes con alto valor cultural, sino porque representan el sustento y se consideran alimentos de reserva en tiempos de escasez. Varias mujeres cuentan como ellas o sus madres van a recoger estos mariscos para que la familia no tenga que comer solamente arroz. La mayoría de estos productos se preparan en guisos y se sirven con arroz, aunque existen distintas recetas para la piangua y otros mariscos, entre las que se incluyen los tamales y el atollado (similar al risotto). Son estos platos los que se mencionan con frecuencia al indagar sobre las comidas típicas y preferidas en el territorio, describiendo con detalle y entusiasmo cómo se preparan y lo agradables que son: "Esto, sí, esto es tan rico", dice María Victoria, relatando cómo a ella le gusta comer cangrejo azul y meón.

\section{Pesca y productos secundarios}

La complementariedad entre la producción agrícola y la pesca es fundamental para la seguridad alimentaria y monetaria. La pesca es más abundante entre los meses de marzo y julio, encontrándose especies tan importantes como el pargo (Lutjanus spp.), la lisa (Mugil cephalus), la sierra del Pacífico (Scomberomorus sierra), la corvina (Ophioscion spp.), la corvinata real (Cynoscion reticulatus), los camarones de aguas poco profundas (Ej. Trachypenaeus sp.), y los langostinos (Ej. Litopenaeus spp.). A pesar del creciente comercio del pescado, los resultados de la encuesta de hogares señalan que el consumo familiar es el uso más frecuente (reportado por todas las familias de pescadores como un $71 \%$ muy importante o un $29 \%$ importante), seguido del intercambio local, ya sea a través de la venta o de regalos, y el comercio (MarViva, 2018).

Mientras que los hombres se dedican principalmente a la captura del pescado, las mujeres se encargan del procesamiento y la preparación del mismo. Es común que el pescado fresco se cocine tanto frito como asado y se sirva acompañado de plátano, yuca o arroz. En el pasado, las técnicas de preservación de este producto que se utilizaban con más frecuencia eran el secado al sol, que aún se realiza, y el ahumado, que ha disminuido en los últimos años. Más allá de su importancia práctica, es bien sabido que estas técnicas generan cambios en la textura y el sabor de los ingredientes, haciendo que estos se destaquen en platos como el tapao de pescado (pescado seco al vapor sobre plátano hervido) y en las sopas. Aunque los precios son más bajos en relación con el pescado fresco, el pescado seco también se vende a vecinos, pueblos indígenas Emberá que vienen a comerciar o compradores urbanos por unos $8000 \mathrm{COP} / \mathrm{kg}$.

De igual forma, la mayoría de hogares en Sivirú producen ron de caña de azúcar (viche) tres veces al año y lo venden por botella $(750 \mathrm{ml} / 8,000 \mathrm{COP})$ o en una medida de 5 galones (130,000 COP) a nivel local o en comunidades vecinas, inclusive en Pizarro. El viche también es importante en la medicina tradicional de las comunidades afrocolombianas del Pacífico ya que se utiliza para producir tinturas de plantas medicinales.

\section{Discusión}

En esta investigación sostenemos que las prácticas cotidianas de aprovisionamiento de las mujeres en Sivirú propenden por una soberanía alimentaria desde el territorio, la cual contribuye a mantener un sistema alimentario local profundamente arraigado en las 
relaciones socioecológicas que reflejan la cultura local y el conocimiento ecológico. La naturaleza política de este estudio representa entonces un área importante de reflexión si se considera lo que se constituye como trabajo dentro del marco de la soberanía alimentaria (Figueroa, 2015; Ngcoya y Kumarakulasingam, 2017; Visser et al., 2015). Así, argumentamos que, aunque normalizadas y en ocasiones subvaloradas, las prácticas cotidianas de aprovisionamiento de las mujeres son fuertemente políticas en al menos dos formas.

En primer lugar, cuando estas se sitúan dentro de un contexto regional y nacional de violencia persistente y desplazamiento forzado, abandono estatal, tendencias de migración ruralurbana y una presión creciente a favor de la integración en una economía monetaria de mercado, cualquier trabajo que las personas realicen para permanecer en su territorio es una forma vital de resistencia. Inclusive con estos desafíos, muchas personas han escogido permanecer en Sivirú, invertir en el sostenimiento de sus familias y de la comunidad, y defender sus visiones de un futuro mejor en lugar de migrar a la ciudad. Aunque ni los miembros de la comunidad ni los líderes usan el lenguaje de la soberanía alimentaria, sí destacan la búsqueda de vidas y medios de vida dignos. La producción a nivel local de alimentos que son culturalmente valiosos a través de huertos caseros y la recolección de alimentos silvestres, las expresiones culinarias producto de estas actividades y el conocimiento tradicional asociado son parte integral de la identidad local que las personas asocian con su bienestar individual y colectivo y sus conexiones con sus territorios ancestrales, lo que es fundamental para sus aspiraciones a futuro. En segundo lugar, la lógica de producción dentro de la práctica de aprovisionamiento de las mujeres es distinta a la de la producción capitalista, dado que sus objetivos principales son el mantenimiento de las relaciones sociales y culturales. A través de la producción de alimentos, las mujeres reproducen espacios y prácticas que sostienen los vínculos con la familia, otros miembros de la comunidad y su territorio, aspectos que hacen viable vivir ahí. Estas estrategias, aunque a veces se cruzan entre sí y pueden incluir mercados capitalistas, trascienden las lógicas relacionadas con la generación de ingresos y la acumulación capitalista (Gibson-Graham 2008). La producción local de alimentos para el consumo propio está permitiendo a los miembros de la comunidad mantener cierto grado de independencia de la economía capitalista de mercado, a pesar de la necesidad del dinero para acceder a algunos bienes materiales.

Mientras que las actividades de aprovisionamiento predominantemente masculinas, como la agricultura y la pesca comercial, tienden a recibir más reconocimiento y apoyo por parte del Estado y actores no estatales, es importante reconocer que las mujeres en Sivirú juegan un papel vital en el mantenimiento de sistemas alimentarios locales y una economía local a través de la producción de alimentos, actividades de cosecha y su labor en la planificación y preparación de comidas. Puntualmente, las mujeres tienden a enfocar sus esfuerzos de trabajo en actividades que se lleven a cabo alrededor de la casa, allí se maneja la producción en huertos caseros, la recolección de alimentos del manglar, la producción de elementos secundarios y se colabora con los hombres del hogar en la agricultura. Similar a los hallazgos de Lewis (2016) en otras partes, muchas mujeres en Sivirú encuentran en estas actividades espacios para el ejercicio de la agencia creativa, el placer, la autoridad y la influencia. Estas prácticas cotidianas individuales y colectivas son integrales y contribuyen al mantenimiento

Turner, K.L., Idrobo, C.J., Desmarais, A.A., y Peredo, A.M. (2020). Soberanía alimentaria desde el territorio: aprovisionamiento, prácticas cotidianas y el papel de las mujeres afrocolombianas en el mantenimiento de sistemas alimentarios. Jangwa Pana, 20(1), 158-185. doi: https://doi.org/10.21676/16574923.3996 
y fortalecimiento del complejo entre conocimiento ecológico tradicional, biodiversidad, relaciones sociales y prácticas culturales, el cual otorga a los sistemas alimentarios afrocolombianos de esta región de Colombia particularidades que sostienen familias, comunidades y modos de vida (Ministerio de Cultura y Fundación ACUA, 2015, 2016).

Académicos y defensores de la soberanía alimentaria señalan los desafíos de profundizar en este tema en diversos contextos y múltiples escalas interrelacionadas (Iles y Montenegro de Wit, 2015; Ngcoya y Kumarakulasingam, 2017). En este sentido, examinar las prácticas y experiencias cotidianas en relación al aprovisionamiento de alimentos permite una exploración de los retos y posibilidades de la soberanía alimentaria en contextos como el de Sivirú. Como Ngcoya y Kumarakulasingam (2017, p. 486) sugieren, ampliar el lente de análisis de la soberanía alimentaria más allá de aquellos procesos políticos "ruidosos": "...nos permite concebir la soberanía alimentaria como una situación que es producto de constelaciones históricas de poder y una respuesta a esta situación en condiciones limitadas." La academia y los movimientos por la soberanía alimentaria se han preocupado en gran medida por el género y la participación de las mujeres, en particular con respecto a su representación en La Vía Campesina y otras organizaciones (Desmarais, 2007). De ahí que nuestro análisis de las actividades de aprovisionamiento de las mujeres se base en estos estudios y extienda al análisis de las prácticas cotidianas de soberanía alimentaria desde el territorio.

Reconocer las contribuciones silenciadas de las mujeres proporciona nuevas perspectivas sobre cómo esta soberanía alimentaria se renueva a través de movilizaciones regionales o nacionales y, quizás predominantemente, por medio de las prácticas cotidianas de aprovisionamiento. Por ejemplo, el conocimiento y la labor de las mujeres en el cultivo de huertos caseros en Sivirú proporcionan un acceso a verduras frescas, frutas, hierbas, proteínas, medicinas y a veces ingresos o bienes intercambiables que a su vez permiten obtener otros alimentos y mantener redes de seguridad social dentro de la comunidad. Las hierbas frescas que cultivan las mujeres son una característica única y muy valorada de la cocina local que no se puede sustituir fácilmente con productos comerciales sin afectar las percepciones locales sobre la calidad de los alimentos y la salud. De hecho, muchos de los entrevistados comentan una preocupación local que tiene que ver con el cambio de dieta en la comunidad y la creciente incidencia de hipertensión, diabetes y otras enfermedades causadas por el alto consumo de sal, azúcar y grasas saturadas. Sin duda, esto resalta la importancia de la producción en huertos caseros para las percepciones locales de bienestar.

Indagar sobre la labor de aprovisionamiento de las mujeres también pone de relieve los desafíos que ellas enfrentan, la complejidad de sus medios de vida y las relaciones entre sus estrategias de subsistencia y su bienestar. La cosecha de piangua es un buen ejemplo de cómo un recurso puede ser el eje fundamental del rebusque de muchas mujeres, pero al mismo tiempo subraya las diferencias entre las mujeres de la comunidad y las complejidades que subyacen a la "elección", el empoderamiento y el beneficio (Agarwal, 2014; Guerra, Blesh, et al. 2017). El significado de esta actividad para mujeres que eligen cosechar ocasionalmente es distinto al de aquellas que recolectan tanta piangua como sea posible para sostener a sus familias y a ellas mismas. Las mujeres describen la cosecha de piangua como parte de su identidad y se llaman a sí mismas piangüeras. Realizar esta actividad que es considerada

Turner, K.L., Idrobo, C.J., Desmarais, A.A., y Peredo, A.M. (2020). Soberanía alimentaria desde el territorio: aprovisionamiento, prácticas cotidianas y el papel de las mujeres afrocolombianas en el mantenimiento de sistemas alimentarios. Jangwa Pana, 20(1), 158-185. doi: https://doi.org/10.21676/16574923.3996 
como difícil y peligrosa, también otorga cierto respeto y autoridad a aquellas mujeres que se dedican a ello - todos los detalles de la recolección de piangua en el manglar también están documentados en otros lugares (Ochoa Camacho et al., 2011). Los miembros de la comunidad en Sivirú, Quibdó y otros lugares se benefician enormemente del conocimiento, trabajo y riesgos asumidos por las piangüeras, ya que se obtiene acceso a alimentos que son apreciados culturalmente y que de otra manera no tendrían. No obstante, para las propias piangüeras la exposición a los peligros conlleva costos para su salud además que las necesidades deben situarse en un rango limitado de opciones disponibles para ellas. Un análisis de una soberanía alimentaria desde el territorio, enfocado en la labor cotidiana de aprovisionamiento que realizan las mujeres, contribuye a aumentar el reconocimiento de sus aportes, ilumina las complejidades que subyacen, y puede evidenciar estrategias y formas de desarrollo que mejoren el bienestar de las mujeres y las comunidades.

Es de resaltar que la conservación de los manglares y la piangua es un eje de gestión de los recursos locales y de planificación de áreas protegidas. Por consiguiente, se están llevando a cabo iniciativas con el fin de regular la cosecha de piangua a través de cierres voluntarios a nivel comunitario y estrategias educativas con piangüeras que contribuyan a establecer mínimos de tamaño de concha y procesos de zonificación vinculados al área protegida el Encanto de los Manglares. Algo importante es que el enfoque en esta y otras regiones ha sido la conservación biológica, por lo que se presta menos atención a mejorar las condiciones de cosecha e intercambio para las recolectoras (Lucero, et al., 2012). Uno de los retos al equilibrar la conservación biológica con los medios de vida local es que existe una mayor presión de recolección en las áreas más cercanas a la comunidad y esto se debe a la relativa facilidad de acceso y a las preocupaciones de seguridad. Si estas preocupaciones no se consideran de forma significativa en procesos de planificación para la conservación, las mujeres que no tienen acceso a otras oportunidades de sustento o a un capital para lanchas de motor, serán afectadas en gran medida al perder el acceso a las zonas de cosecha. De forma similar, la exposición a peligros como el pejesapo podría reducirse trabajando con piangüeras en el diseño de equipos de seguridad que sean apropiados y funcionales, por ejemplo guantes protectores duraderos. Por otro lado, mejorar los precios que reciben las mujeres por vender piangua también puede contribuir a mejorar sus medios de vida.

\section{Conclusiones}

En el Bajo Baudó, los proyectos de desarrollo a nivel regional relacionados con la conservación y la planificación del uso de los recursos necesitan prestarle mayor atención al sistema alimentario al crear las condiciones legales que regulan la utilización y el acceso, particularmente a recursos costeros y marinos. Sin duda, apoyar la pesca artesanal como una actividad de producción de alimentos a pequeña escala es un factor determinante en DRMI y en otros procesos. Sin embargo, las actividades cotidianas de aprovisionamiento de las mujeres respaldan muchos aspectos del sistema alimentario local. La atención secundaria que se presta a la labor de aprovisionamiento de las mujeres por parte de actores estatales y no estatales, incluso a nivel comunitario, sugiere que las mujeres y sus hogares pueden verse afectados de gran manera por los esfuerzos regionales de planificación territorial relacionados con la soberanía alimentaria, en el caso de que sus actividades y necesidades no sean cuidadosa y significativamente consideradas en estos procesos. Al observar la práctica diaria, también se resaltan entonces las posibles contradicciones entre el trabajo micro y 
macro de soberanía alimentaria. Reconocer cómo las actividades económicas y las prácticas cotidianas de las mujeres contribuyen a las luchas locales y regionales por la soberanía alimentaria ayuda a ampliar el lente del análisis de la soberanía alimentaria y los dominios de acción de la misma con el fin de comprender mejor el trabajo de las mujeres y sus actividades de subsistencia y, al hacerlo, apoyar la renovación de la soberanía alimentaria más allá de un discurso político hacia una soberanía alimentaria desde el territorio.

\section{Agradecimientos}

Nuestros más sinceros agradecimientos al Consejo Comunitario y a la gente de Sivirú por permitirnos emprender este proyecto en su comunidad, por compartir sus conocimientos y experiencias con nosotros y por su hospitalidad. También agradecemos a la Fundación MarViva Colombia por su colaboración y apoyo logístico en la realización de esta investigación y a la Fundación Activos Culturales Afro - ACUA por su continuo apoyo. Muchas gracias a Diana Carolina Castaño-Alzate por su trabajo en la traducción de este articulo y a María Juliana Rubiano por su ayuda con las transcripciones de entrevistas y a la Facultad de Estudios Ambientales de la Universidad de Victoria, por acoger a Turner durante su estancia postdoctoral. Esta investigación fue posible gracias a la financiación del Fondo de Apoyo a Profesores Asistentes (FAPA) de la Universidad de los Andes (Idrobo: \# P16.P16.303622.005/01), el programa de Cátedra de Investigación Canadiense en Derechos Humanos, Justicia Social y Soberanía Alimentaria (Canada Research Chair in Human Rights, Social Justice and Food Sovereignty), y las beca postdoctoral del Consejo de Investigación de Ciencias Sociales y Humanidades de Canadá (Social Sciences and Humanities Research Council of Canada Postdoctoral Fellowships; Turner: \# 756-2017-03).

\section{Referencias}

Agarwal, B. (2014). Food sovereignty, food security and democratic choice: Critical contradictions, difficult conciliations. Journal of Peasant Studies, 41(6), 1247-1268.

Akram-Lodhi, A. H., y Kay, C. (2009). Peasants and globalization: Political economy, rural transformation and the agrarian question. New York, New York: Routledge.

Asher, K. (2009). Black and green: Afro-Colombians, development, and nature in the Pacific lowlands. Durham, NC: Duke University Press.

Ayres, J., \& Bosia, M. J. (2011). Beyond global summitry: Food sovereignty as localized resistance to globalization. Globalizations, 8(1), 47-63.

Bezner Kerr, R., Hickey, C., Lupafya, E., y Dakishoni, L. (2019). Repairing rifts or reproducing inequalities? Agroecology, food sovereignty, and gender justice in Malawi. The Journal of Peasant Studies, 1-20. https://doi.org/10.1080/03066150.2018.1547897

CODECHOCO, MarViva, WWF, Naturaleza y Cultura Internacional, WCS, y CORPARIEN. (2017). Propuesta para la declaratoria del Distrito Regional de Manejo Integrado "Encanto de los Manglares del Bajo Baudó." CODECHOCO - Corporación Autónoma Regional para el Desarrollo Sostenible del Chocó.

Conway, J. M. (2018). When food becomes a feminist issue: popular feminism and subaltern agency in the World March of Women. International Feminist Journal of Politics, 20(2), 188-203. https://doi.org/10.1080/14616742.2017.1419822

Creswell, J. (2014). Research Design: Qualitative, Quantitative, and Mixed Methods Approaches. Thousand Oaks, CA.: Sage Publications Ltd.

Turner, K.L., Idrobo, C.J., Desmarais, A.A., y Peredo, A.M. (2020). Soberanía alimentaria desde el territorio: aprovisionamiento, prácticas cotidianas y el papel de las mujeres afrocolombianas en el mantenimiento de sistemas alimentarios. Jangwa Pana, 20(1), 158-185. doi: https://doi.org/10.21676/16574923.3996 
Davidson-Hunt, I. J., Idrobo, C. J., y Turner, K. L. (2017). The creativity of everyday life in crafting resilient food systems: a framework and case from the Atlantic forest coast of Brazil. Human Ecology, 45(5), 601-612.

Desmarais, A. A. (2007). La Via Campesina: Globalization and the power of peasants. Black Point, Nova Scotia: Fernwood Publishing and Pluto Press.

Escobar, A. (2008). Territories of difference: Place, movements, life, redes. USA: Duke University Press.

Fanon, F. (2008). Black skin, white masks. New York: Grove Press.

Federici, S. (2014). La inacabada revolución feminista: mujeres, reproducción social y lucha por la común. Bogotá, DC: Ediciones Desde Abajo.

Figueroa, M. (2015). Food sovereignty in everyday life: Toward a people-centered approach to food systems. Globalizations, 12(4), 498-512.

Gibson-Graham, J. K. (2008). Diverse economies: performative practices for other worlds. Progress in Human Geography, 32(5), 613-632.

Grey, S., y Patel, R. (2015). Food sovereignty as decolonization: Some contributions from Indigenous movements to food system and development politics. Agriculture and Human Values, 32(3), 431-444.

Guerra, J., Blesh, J., Schmitt Filho, A. L., y Wittman, H. (2017). Pathways to agroecological management through mediated markets in Santa Catarina, Brazil. Elem Sci Anth, 5.

Howard, P. L. (Ed.). (2003). Women and Plants: Gender relations in biodiversity management and conservation. London, UK: Zed Books.

Human Rights Watch. (2017, June 7). Colombia: Armed Groups Oppress Riverside Communities - Families displaced as groups dispute control of river [Homepage]. Retrieved from https://www.hrw.org/news/2017/06/07/colombiaarmed-groupsoppress-riverside-communities

Iles, A., y Montenegro de Wit, M. (2015). Sovereignty at what scale? An inquiry into multiple dimensions of food sovereignty. Globalizations, 12(4), 481-497.

IPES-Food. (2016). From uniformity to diversity: A paradigm shift from industrial agriculture to diversified agroecological systems. International Panel of Experts on Sustainable Food $\quad$ Systems. $\quad$ Retrieved from http://www.ipesfood.org/_img/upload/files/UniformityToDiversity_FULL.pdf.

Kuokkanen, R. (2011). Indigenous economies, theories of subsistence, and women: Exploring the social economy model for indigenous governance. American Indian Quarterly, 35(2), 215-240.

Lemke, S., y Delormier, T. (2017). Indigenous Peoples' food systems, nutrition, and gender: Conceptual and methodological considerations. Maternal \& Child Nutrition, 13(p.e12499).

Lewis, D. (2016). Bodies, matter and feminist freedoms: Revisiting the politics of food. Agenda, 30(4), 6-16.

Lucero, C., Cantera, J., y Neira, R. (2012). Pesquería y crecimiento de la piangua (Arcoida: Arcidae) Anadara tuberculosa en la Bahía de Málaga del Pacífico colombiano, 20052007. Revista de Biología Tropical, 60(1).

Magdoff, F., Bellamy Foster, J., y Buttel, F. H. (Eds.). (2000). Hungry for profit: The agribusiness threat to farmers, food, and the environment. New York, New York: Monthly Review Press.

Turner, K.L., Idrobo, C.J., Desmarais, A.A., y Peredo, A.M. (2020). Soberanía alimentaria desde el territorio: aprovisionamiento, prácticas cotidianas y el papel de las mujeres afrocolombianas en el mantenimiento de sistemas alimentarios. Jangwa Pana, 20(1), 158-185. doi: https://doi.org/10.21676/16574923.3996 
MarViva. (2018). Línea base para la estructura de gobierno local del Distrito Regional de Manejo Integrado Encanto de los Manglares del Bajo Baudó (Proyecto: PLAN por un Pacífico Sostenible). Bogotá, Colombia: MarViva and PLAN International - Por la niñez colombiana.

Masson, D., Paulos, A., y Beaulieu Bastien, E. (2017). Struggling for food sovereignty in the World March of Women. The Journal of Peasant Studies, 44(1), 56-77.

Ministerio de Cultura, y Fundación ACUA. (2015). Saberes y Sabores del Pacífico Colombiano: Guapi-Quibdó. Bogotá, DC: Ministerio de Cultura, República de Colombia. Retrieved from http://patrimonio.mincultura.gov.co/SiteAssets/Paginas/Publicacionesbibliotecacocinas/Libro\%20Pac\%C3\%ADfico.pdf

Ministerio de Cultura, y Fundación ACUA. (2016). Biodiversidad, Cocina e Identidad en el Pacífico Colombiano: La Cocina Tradicional de Tumaco, Nariño y Buenaventura, Valle del Cauca. Bogotá, DC: Ministerio de Cultura, República de Colombia. Retrieved from http://patrimonio.mincultura.gov.co/Lineas-de-Accion/Politica-parael-

Conocimiento/Documents/Publicaciones/Biodiversidad\%20del\%20Pac\%C3\%ADfico .pdf

Ministerio del Trabajo, y PNUD. (2013). Perfil productivo: Municipio Bajo Baudó - Insumo para el diseño de las estrategias y alternativas para la generación de empleo a las víctimas de la violencia. Ministerio de Trabajo and Programa de las Naciones Unidas para el Desarrollo (PNUD).

Narotzky, S. (2005). Provisioning. In J. G. Carrier (Ed.), A handbook of economic anthropology (pp. 78-93). Cheltenham, UK: Edward Elgar Publishing.

Ngcoya, M., \& Kumarakulasingam, N. (2017). The Lived Experience of Food Sovereignty: Gender, Indigenous Crops and Small-Scale Farming in Mtubatuba, South Africa. Journal of Agrarian Change, 17(3), 480-496.

Ochoa Camacho, A. L., Martínez Díaz, A. I., Gutiérrez Quintero, B., Fernández Amador, G., Madden Arias, L., Marchena Alpizar, L., ... Ortiz Murillo, P. A. (2011). Mujeres rurales, tierra y producción: participación de mujeres rurales en cadenas de valor (Vol. 2). Asociación para el desarrollo de las mujeres negras costarricenses and FIDA. Retrieved from http://biblioteca.ribei.org/823/

Ong, A. (2010). Spirits of resistance and capitalist discipline: Factory women in Malaysia (Second Edition). Albany, NY: Suny Press.

Oslender, U. (2016). The geographies of social movements: Afro-Colombian mobilization and the aquatic space. Durham, NC: Duke University Press.

Park, C. M. Y., White, B., y Julia. (2015). We are not all the same: taking gender seriously in food sovereignty discourse. Third World Quarterly, 36(3), 584-599.

Patel, R. C. (2012). Food sovereignty: power, gender, and the right to food. PLoS Medicine, 9(6), e1001223.

Peredo, A. M., y Chrisman, J. J. (2006). Toward a theory of community-based enterprise. Academy of Management Review, 31(2), 309-328.

Peredo, A. M., y McLean, M. (2013). Indigenous Development and the Cultural Captivity of Entrepreneurship. Business and Society, 52(4), 592-620.

Portman, A. (2018). Food Sovereignty and Gender Justice. Journal of Agricultural and Environmental Ethics, 31(4), 455-466.

Turner, K.L., Idrobo, C.J., Desmarais, A.A., y Peredo, A.M. (2020). Soberanía alimentaria desde el territorio: aprovisionamiento, prácticas cotidianas y el papel de las mujeres afrocolombianas en el mantenimiento de sistemas alimentarios. Jangwa Pana, 20(1), 158-185. doi: https://doi.org/10.21676/16574923.3996 
PWESCR. (2011). Locating women's livelihoods in the Human Rights framework. New Delhi: PWESCR - Programme on Women's Economic, Social and Cultural Rights. Retrieved from http://www.pwescr.org/PWESCR_Discussion\%20Paper\%20Final_307-2011.pdf

República de Colombia. Ley 70 de 1993 (1993). Retrieved from https://www.minagricultura.gov.co/Normatividad/Leyes/Ley\%2070\%20de\%201993. pdf

Robbins, M. J. (2015). Exploring the 'localisation' dimension of food sovereignty. Third World Quarterly, 36(3), 449-468.

Sahlins, M. (1972). Stone Age Economics. Chicago, IL: Aldine-Atherton.

Sahlins, M. (1998). The original affluent society. In J. M. Gowdy (Ed.), Limited wants, unlimited means: A reader on hunter-gatherer economics and the environment (pp. 541). Washington, D.C.: Island Press.

Schwendler, S. F., y Thompson, L. A. (2017). An education in gender and agroecology in Brazil's Landless Rural Workers' Movement. Gender and Education, 29(1), 100-114.

Scott, J. C. (1985). Weapons of the weak: Everyday forms of peasant resistance. New Haven: Yale University Press.

Sylvester, O., Segura, A. G., y Davidson-Hunt, I. (2016). Complex relationships among gender and forest food harvesting: insights from the Bribri Indigenous Territory, Costa Rica. International Forestry Review, 18(2), 247-260.

van der Ploeg, J. D. (2018). The new peasantries: Struggles for autonomy and sustainability in an era of empire and globalization (Second Edition). London, UK: Earthscan.

Visser, O., Mamonova, N., Spoor, M., \& Nikulin, A. (2015). 'Quiet food sovereignty' as food sovereignty without a movement? Insights from post-socialist Russia. Globalizations, 12(4), 513-528.

Wall, J. R., Aksoy, E. B., Köse, N., Okan, T., y Köse, C. (2018). What Women Know that Men Do Not about Chestnut Trees in Turkey: A Method of Hearing Muted Knowledge. Journal of Ethnobiology, 38(1), 138-154.

Wittman, H., Desmarais, A. A., y Wiebe, N. (Eds.). (2010). Food Sovereignty: Reconnecting Food Nature and Community. Fernwood Publishing.

Turner, K.L., Idrobo, C.J., Desmarais, A.A., y Peredo, A.M. (2020). Soberanía alimentaria desde el territorio: aprovisionamiento, prácticas cotidianas y el papel de las mujeres afrocolombianas en el mantenimiento de sistemas alimentarios. Jangwa Pana, 20(1), 158-185. doi: https://doi.org/10.21676/16574923.3996 